\title{
System-level design studies for large rotors
}

\author{
Daniel S. Zalkind ${ }^{1}$, Gavin K. Ananda ${ }^{2}$, Mayank Chetan ${ }^{3}$, Dana P. Martin ${ }^{4}$, Christopher J. Bay ${ }^{5}$, \\ Kathryn E. Johnson ${ }^{4,5}$, Eric Loth ${ }^{6}$, D. Todd Griffith ${ }^{3}$, Michael S. Selig ${ }^{2}$, and Lucy Y. Pao ${ }^{1}$ \\ ${ }^{1}$ Department of Electrical, Computer \& Energy Engineering, \\ University of Colorado Boulder, Boulder, CO 80309, USA \\ ${ }^{2}$ Department of Aerospace Engineering, University of Illinois Urbana-Champaign, Champaign, IL 61820, USA \\ ${ }^{3}$ Department of Mechanical Engineering, University of Texas at Dallas, Richardson, TX 75080, USA \\ ${ }^{4}$ Department of Electrical Engineering, Colorado School of Mines, Golden, CO 80401, USA \\ ${ }^{5}$ National Wind Technology Center, National Renewable Energy Laboratory, Golden, CO 80401, USA \\ ${ }^{6}$ Department of Mechanical and Aerospace Engineering, \\ University of Virginia, Charlottesville, VA 22904, USA
}

Correspondence: Daniel S. Zalkind (dan.zalkind@gmail.com)

Received: 4 January 2019 - Discussion started: 6 February 2019

Revised: 2 August 2019 - Accepted: 26 September 2019 - Published: 11 November 2019

\begin{abstract}
We examine the effect of rotor design choices on the power capture and structural loading of each major wind turbine component. A harmonic model for structural loading is derived from simulations using the National Renewable Energy Laboratory (NREL) aeroelastic code FAST to reduce computational expense while evaluating design trade-offs for rotors with radii greater than $100 \mathrm{~m}$. Design studies are performed, which focus on blade aerodynamic and structural parameters as well as different hub configurations and nacelle placements atop the tower. The effects of tower design and closed-loop control are also analyzed. Design loads are calculated according to the IEC design standards and used to create a mapping from the harmonic model of the loads and quantify the uncertainty of the transformation.

Our design studies highlight both industry trends and innovative designs: we progress from a conventional, upwind, three-bladed rotor to a rotor with longer, more slender blades that is downwind and two-bladed. For a $13 \mathrm{MW}$ design, we show that increasing the blade length by $25 \mathrm{~m}$, while decreasing the induction factor of the rotor, increases annual energy capture by $11 \%$ while constraining peak blade loads. A downwind, two-bladed rotor design is analyzed, with a focus on its ability to reduce peak blade loads by $10 \%$ per $5^{\circ}$ of cone angle and also reduce total blade mass. However, when compared to conventional, three-bladed, upwind designs, the peak main-bearing load of the upscaled, downwind, two-bladed rotor is increased by $280 \%$. Optimized teeter configurations and individual pitch control can reduce non-rotating damage equivalent loads by $45 \%$ and $22 \%$, respectively, compared with fixed-hub designs.
\end{abstract}

Copyright statement. Christopher J. Bay's copyright for this publication is transferred to Alliance for Sustainable Energy, LLC.

\section{Introduction}

Wind turbines are large, dynamic structures that experience significant structural loading on their component parts. Design choices impact the loading on each of these parts. We present a model for the rapid computation of wind turbine design loads, which we use to quantify the effect of design trade-offs associated with different rotor concepts. The economics of wind energy have enabled larger wind turbine sizes, generator ratings, and blade lengths. Longer blades are economical simply because they capture more power more often. A wind turbine's annual energy production (AEP) is the total amount of energy captured by a wind turbine during one year. Increasing the power capture is the primary driver of reducing the cost of wind energy $(\mathrm{COE})$ 
$\mathrm{COE}=\frac{\mathrm{CapEx}+\mathrm{OpEx}}{\mathrm{AEP}}$,

where capital expenditures (CapEx) and operational expenditures $(\mathrm{OpEx})$ make up the cost of building and running a wind turbine. Our goal is to minimize the cost of wind energy, enabling the sale of more wind turbines in an effort to make low-cost energy more available.

Operational expenditures are non-negligible but make up roughly $15 \%$ of the total cost, according to a study of the average 2015 offshore wind turbine (Mone et al., 2015). Capital expenditures include the wind turbine parts and balanceof-station costs. Balance-of-station costs account for about $55 \%$ of the total cost and include electrical infrastructure, assembly, and substructure costs. Wind turbine parts (tower, nacelle, blades, etc.) comprise about $30 \%$ of the overall cost of an offshore, fixed-bottom wind plant (Mone et al., 2015). The small cost contribution of the wind turbine blades, which is only a fraction of the cost of the wind turbine parts, and the significant effect of wind turbine blades on AEP contribute to the economics that enable larger and larger blades.

However, longer blades require additional structural reinforcement, which increases the blade weight, resulting in larger loads experienced by other wind turbine components like the hub, main bearing, yaw bearing, and tower. Various innovations have enabled lower weight blades; these innovations are then used to subsequently design larger blades that capture more power. Still, the wind turbine components must survive extreme structural loading and last 20-30 years. Wind turbine components are often designed by various engineering teams based on loads from aeroelastic simulations, making wind turbine design a large, distributed design task.

The aerodynamic and structural aspects of wind turbines must be designed and controlled so that the structural loading for a design is feasible. There is a large interdependence between these design aspects (aerodynamic, structural, and controls) and on the various wind turbine components, which has led to numerous design optimization studies. These studies focus primarily on blade aerodynamic and structural design, e.g., in Ning et al. (2014) and Pavese et al. (2017). Some incorporate dynamic control effects, like Tibaldi et al. (2015) and Bortolotti et al. (2016). System engineering tools, like HAWTOpt2 (Døssing, 2011), WISDEM (Dykes et al., 2014), and Cp-Max (Bortolotti et al., 2016), have been developed to handle the large number of design variables but often compute structural loads using simplified scaling rules, conservative static calculations, or many nonlinear aeroelastic simulations. A full set of design load cases (DLCs), specified by the International Electrotechnical Commission (2005) (IEC) in design standards, and simplified for research purposes in Natarajan et al. (2016), can include up to 2000 simulations, which can be costly in terms of computational effort, resulting in long design cycle times. Often the results of these simulations do not fully elucidate the root cause of problematic load cases on the affected turbine component. An attempt to distill the DLCs into a reduced basis for design loads in an optimization framework was presented in Pavese et al. (2016).

We describe an alternative load estimation procedure, based on a set of simulations with a constant, sheared wind inflow that reflects the main drivers of wind turbine loads and the effects of design changes on global wind turbine loads. Since both turbulent and constant wind effects contribute to structural loading and the effect of turbulence has been well studied recently, e.g., in Dimitrov et al. (2018) and Robertson et al. (2018), we will focus our effort on how turbine model changes impact the harmonic loads caused by wind shear and turbine self-weight. We do this by decomposing the turbine loads from constant, sheared wind inputs into their harmonic components, i.e., the load amplitude of the $i$ th per revolution $(i \mathrm{P})$ load signal. These signals have been used for control (Bottasso et al., 2013), stability analysis (Bottasso and Cacciola, 2015), and wind field estimation (Bertelè et al., 2017). Here, we use the same signals to develop a mapping, or transformation, from the harmonic loads to the DLC-simulated design loads to understand the effect that changing the underlying turbine model has on structural loading.

The power and load estimation procedure developed in this study is used to analyze concepts for enabling rotor radii greater than $100 \mathrm{~m}$. Recently, large rotor concepts have been studied in the European projects UpWind and INNWIND. The Danish Technical University (DTU) $10 \mathrm{MW}$ reference wind turbine (RWT) (Bak et al., 2013) was provided as a design basis for large rotors to test design methods and tools. The DTU $10 \mathrm{MW}$ RWT has motivated studies that focus on optimization methods (Zahle et al., 2015) and active (McWilliam et al., 2018) and passive (Pavese et al., 2017) load control methods, but the resulting designs from these studies do not deviate far from the base rotor model. A twobladed, downwind, teetering hub configuration of the DTU $10 \mathrm{MW}$ RWT was developed, which shows that a teetering hub can greatly reduce the unbalanced loading on the main shaft and blade root (Bergami et al., 2014). Bergami et al. (2014) suggest that the tower stiffness distribution needs to be redesigned in order to avoid a resonance at the twice-perrevolution $(2 \mathrm{P})$ rotor harmonic and that two-bladed rotors (without teeter) increase loading on the main shaft significantly.

A couple of $20 \mathrm{MW}$ rotor designs have been proposed in the literature. Sieros et al. (2012) and Peeringa et al. (2011) use classical similarity scaling rules to upscale conventional turbines. Both conclude that loads due to self-weight will increase significantly with blade length and drive component design as turbines grow larger. Specifically, edgewise blade loads and the effect of wind shear are magnified for larger rotor sizes.

A series of design studies at Sandia National Laboratories (SNL) detailed the structural design of a $100 \mathrm{~m}$ blade with the goal of reducing the blade mass. First, a classically upscaled blade was given a detailed composite lay-up and 
tested against DLCs (Griffith and Ashwill, 2011). Next, a series of design innovations reduced the blade mass from 76 metric tons to 49 metric tons, utilizing carbon-fiber reinforcement (Griffith, 2013a), advanced core materials (Griffith, 2013b), and flatback airfoils (Griffith and Richards, 2014).

Another concept to reduce mass-scaling issues is a highly coned, downwind rotor, which has shown that blade loads can be reduced by converting large cantilever loads at the blade root into tensile loads along the span of the blade (Ichter et al., 2016; Loth et al., 2017b). We will analyze this concept and its effect on the structural loading of the other wind turbine components besides the blades.

There are few openly published documents that quantify the effects of significant design changes and detailed rotor upscaling on the various wind turbine components. We will quantify the effect of aerodynamic changes, including the blade length, axial induction, cone angle, and number of blades, as applied to both upwind and downwind rotors. A simplified structural model will demonstrate the effect of structural reinforcement on blade mass and loads. The upscaled structural model must provide enough stiffness to compensate for the increasing edgewise blade loads of large rotors. We quantify the effect of changes to the hub by looking at three-bladed and two-bladed rotor configurations, and consider the relative benefits of a teeter hinge or individual pitch control for the latter. Finally, we show how the nacelle placement atop the tower and control schemes can impact the loads on the tower and yaw bearing.

We believe this study will contribute an early stage design model for evaluating design concepts with less computational effort by eliminating hundreds of DLC simulations. The simplified load model provides a qualitative understanding of the relationship between wind turbine structural loads as they progress from the blades to the substructure, highlighting the wind speeds where peak and fatigue loads are most problematic. A designer could use the simplified model to explore the design space and develop an initial wind turbine model for use in a more detailed load analysis. We map the harmonic loads to a set of loads found using operational design load case simulations and quantify the uncertainty. Quantitative design studies evaluate the effect of increased blade size and power capture on global wind turbine loads, as well as the design trade-offs associated with two-bladed wind turbines, teeter hinges, and individual pitch control.

We will present the baseline models used for comparison and our general design direction in Sect. 2. Section 3 will outline the tools used for design and simulation and will also provide environmental site specifics. A description of the control scheme used throughout the article is presented in Sect. 4. The harmonic model is described in Sect. 5, and in Sect. 6 the transformation from harmonic loads to DLC-simulated design loads is described. The set of design studies is described in Sect. 7, leading to studies of blade loads and power capture (Sect. 8), hub and main-bearing loads (Sect. 9), yaw-bearing loads (Sect. 10), and tower loads (Sect. 11). A discussion of the model's limitations and potential use is provided in Sect. 12, followed by conclusions in Sect. 13.

\section{Baseline models and design direction}

It is useful to start from established designs when doing comparative analysis. In Sect. 8.2, in lieu of a full structural lay-up design, we will use these baseline models for scaling the distributed structural properties of rotor blades. For three-bladed rotors, we will use a conventional rotor design (CONR-13) as a starting point. The CONR-13 is the culmination of a series of design studies aimed at designing a lightweight $100 \mathrm{~m}$ blade; it utilizes flatback airfoils, carbonfiber reinforcement, and advanced core materials to reduce the blade mass below state-of-the-art scaling trends. The full design is described in Griffith and Richards (2014). The distributed blade structural properties of the CONR-13 will be used for all three-bladed rotors in this study.

A downwind, two-bladed rotor was developed with similar structural advances but with the goal of reducing the total blade mass by at least $25 \%$ compared to the CONR-13 (Griffith, 2017). The blade was designed to enable segmentation, ultralight design, and a morphing rotor; we refer to this design as the SUMR-13A. The initial aerodynamic design is presented in Ananda et al. (2018). We have slightly modified the initial design to have a downwind cone angle of $5^{\circ}$ for the purposes of the design studies presented later. The distributed structural parameters of the SUMR-13A blade were used as a basis for scaling all two-bladed rotors in this study. A summary of both baseline models is shown in Table 1 and are drawn to scale in Fig. 1. Both rotors were structurally validated to check strain limits, panel buckling, flutter, and fatigue.

In the remainder of this paper, we will evaluate designs aimed at

1. increasing the energy capture and

2. reducing the wind turbine component loads.

To reduce the cost of energy in Eq. (1), it is most important to increase energy capture (AEP). Industry trends suggest a continued increase in blade length, leading to greater loads on all turbine components. Structural loads contribute to component design and capital cost (CapEx) but require detailed design and cost models for each individual part. Instead of a detailed cost analysis, which is specific to the component supplier and subject to uncertainty, we will develop a larger rotor design, called the SUMR-13B, described in Sect. 8.1, and then quantify the changes to global wind turbine loads and power capture while exploring techniques to reduce those loads. 
Table 1. Turbine models and environmental parameters used throughout this article.

\begin{tabular}{llll}
\hline Turbine model & CONR-13 & SUMR-13A & SUMR-13B \\
\hline Rated power & $13.2 \mathrm{MW}$ & $13.2 \mathrm{MW}$ & $13.2 \mathrm{MW}$ \\
Rated rotor speed & $7.44 \mathrm{rpm}$ & $9.90 \mathrm{rpm}$ & $7.99 \mathrm{rpm}$ \\
Rated wind speed & $11.3 \mathrm{~ms}^{-1}$ & $11.3 \mathrm{~ms}^{-1}$ & $10.3 \mathrm{~ms}^{-1}$ \\
Hub height & $142.4 \mathrm{~m}$ & $142.4 \mathrm{~m}$ & $142.4 \mathrm{~m}$ \\
Rotor radius & $102.5 \mathrm{~m}$ & $101.2 \mathrm{~m}$ & $125.4 \mathrm{~m}$ \\
Rotor position & Upwind & Downwind & Downwind \\
Blade mass & $49.5 \mathrm{Mg}$ & $51.8 \mathrm{Mg}$ & $83.2 \mathrm{Mg}$ \\
Number of blades & 3 & 2 & 2 \\
Max chord & $5.23 \mathrm{~m}$ & $7.22 \mathrm{~m}$ & $6.79 \mathrm{~m}$ \\
Cone angle & $-2.5^{\circ}$ & $5^{\circ}$ & $12.5^{\circ}$ \\
\hline
\end{tabular}

Environmental parameters

\begin{tabular}{ll}
\hline Wind turbine site class & Class IIB \\
Cut-in, cut-out wind speed & $3,25 \mathrm{~ms}^{-1}$ \\
Mean wind speed at $50 \mathrm{~m}$, hub height & $7.87,9.11 \mathrm{~ms}^{-1}$ \\
Weibull shape, scale factor & $2.17,10.3$ \\
Turbulence intensity at $15 \mathrm{~ms}^{-1}$ & 0.14 \\
\hline
\end{tabular}

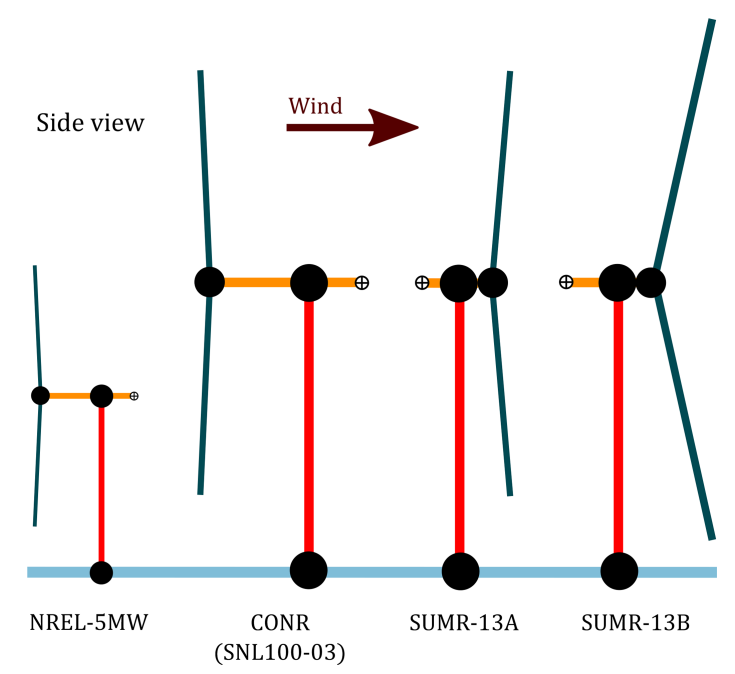

Figure 1. Illustrations of the turbines in this study, along with the National Renewable Energy Laboratory (NREL) $5 \mathrm{MW}$ reference turbine (Jonkman et al., 2009) for comparison. Tower heights, rotor radii, and cone angles are drawn to scale; overhangs and nacelle center of masses are enlarged for comparison.

\section{Design and simulation tools, wind turbine environment}

Aerodynamic design was performed using two inverse design tools: PROPID and PROFOIL. PROPID (Selig and Tangler, 1995; Selig, 1995) is an inverse rotor design tool that enables a rotor geometry to be designed based on desired performance specifications like available power, tip speed ratio, wind speed distribution, axial induction, airfoils used, and desired lift distribution along the blade. PROFOIL (Drela and Giles, 1987) is an inverse airfoil design tool. It allows for the design of airfoil geometries based on prescribed velocity distributions and desired geometric (thickness and camber) and aerodynamic properties. Airfoil geometries output using PROFOIL are analyzed using XFOIL (Drela, 1989) and iterated on using PROFOIL until a final converged design is obtained.

Aeroelastic simulations were performed using the latest version of FAST (Jonkman, 2013). Different FAST modules couple the wind inflow with aerodynamic and elastic solvers that compute the structural loading on the wind turbine. Turbulent wind inputs are generated using TurbSim (Jonkman and Kilcher, 2012). A recent FAST-based, wind-tunnel-validated approach has shown that, compared with turbulence, tower shadow effects are relatively small (Noyes et al., 2018). Thus, for simplicity, we have omitted the tower shadow model from our analysis in order to focus on the influence of the more important harmonic and turbulent loads. Control inputs are provided to FAST through a Matlab/Simulink interface that processes FAST outputs and performs closed-loop control. Fatigue results are computed using MLife (Hayman, 2012), which uses a rain-flowcounting algorithm to determine load cycles and extrapolates them over the lifetime of the wind turbine.

To properly compute lifetime fatigue and annual energy production, the wind turbine environment must be provided. The rotors in this study are all designed to be placed off the coast of Virginia, USA. The site corresponds to a Class IIB turbine rating (International Electrotechnical Commission, 2005), with mean and turbulent wind speed characteristics shown in Table 1.

\section{Closed-loop control}

To simulate turbine design loads and power capture, a closedloop control scheme is necessary. In below-rated conditions, the generator torque $\tau_{\mathrm{g}}$ is controlled so that the rotor speed $\omega$ is optimal for power capture, following the typical $\tau_{\mathrm{g}}=k \omega^{2}$ law for most of the below-rated operating region, before transitioning to above-rated conditions (Pao and Johnson, 2011). For simplicity, this is implemented as a look-up table, though more sophisticated methods exist. The look-up table is altered to avoid a critical rotor speed for two-bladed rotors only (see Fig. 2b; Sect. 11 provides more details). The generator rated power of $13.2 \mathrm{MW}$ and rated speed of $1173.7 \mathrm{rpm}$ are assumed to be constant for all the turbines in this study. The gearbox ratio of each turbine is changed to enable operation at the aerodynamically optimal rated rotor speed.

In above-rated wind speeds, the pitch angle is controlled to regulate the rotor speed to its rated value using a gainscheduled proportional-integral (PI) controller. The gains of the PI controller are set so blade fatigue is minimized, subject to a constraint on the maximum generator speed (Zalkind et al., 2017). We have chosen this control architecture, which is the same for all rotors, so that it can be easily tuned for 

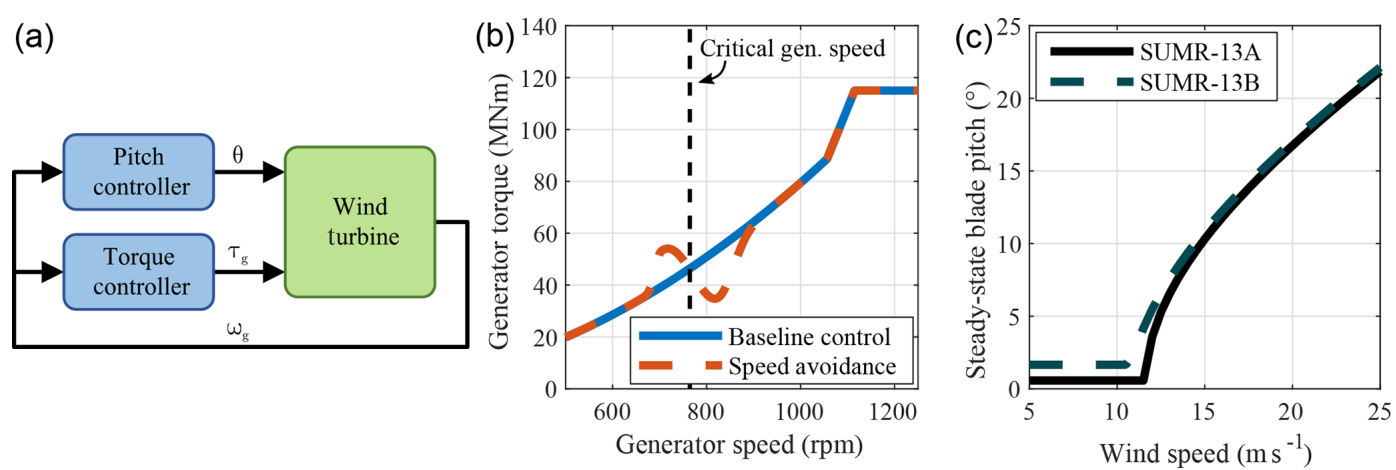

Figure 2. Baseline control block diagram, where $\theta$ is the pitch angle, $\tau_{\mathrm{g}}$ is the generator torque, and $\omega_{\mathrm{g}}$ is the measured generator speed (a). The torque control signal (b) for baseline control (blue) and speed avoidance control (red) to avoid the critical generator speed. Steady-state blade pitch angles (c) for the SUMR-13A and SUMR-13B.

many rotors in the same way. The optimal generator torque control gain $k$ is computed using rotor parameters, and the PI pitch control gains are tuned using a subset of the DLC 1.2 turbulent simulations. The control architecture (as shown in Fig. 2a) is adapted from the National Renewable Energy Laboratory (NREL) $5 \mathrm{MW}$ baseline controller (Jonkman et al., 2009), which is commonly used as a reference to compare new controller designs. While this baseline control may not necessarily be the best possible controller, it allows us to focus on the power and load sensitivity to model changes.

Using closed-loop control for load simulations is important because peak loads often occur near the transition between below- and above-rated operation. With a constant generator rating $(13.2 \mathrm{MW})$, different rotors transition from below- to above-rated conditions at different wind speeds. Additional control signals, like individual pitch control (IPC) signals, are added to the baseline control signals in Fig. 2a.

A controller is also necessary for computing design loads in turbulent DLC simulations, where wind speed changes, or gusts, must be adequately controlled. Often, peak loads are caused by a negative gust, or lull, which we show in Fig. 3 . During a decrease in wind speed, the rotor slows and the pitch decreases to its optimal power position. When the decrease in wind speed is followed by a positive gust, the pitch control must react quickly to regulate rotor speed. We model the actuator of each rotor in this study as a second-order Butterworth filter with a cut-off frequency of $0.25 \mathrm{~Hz}$. The pitch actuator has a maximum pitch rate limit of $4^{\circ} \mathrm{s}^{-1}$; maximum pitch rates between 1 and $3^{\circ} \mathrm{s}^{-1}$ were recorded in the turbulent simulations that were run. This decrease and then increase in wind speed creates a condition where there is an above-rated wind speed but a below-rated pitch angle setting, resulting in a large thrust force on the rotor and high loads. To capture the effect that closed-loop control has on design loads as rotor changes are made, we use the same control architecture for computing loads using the harmonic model (Sect. 5) and for turbulent DLC simulations (Sect. 6), updating the controller parameters based on the rotor parameters.

\section{Harmonic model for load estimation}

Load simulations according to the DLCs can be time consuming, so we have developed a simplified model to estimate the loads on wind turbine components more quickly for evaluating design trade-offs across a wide range of parameters. In this section, we describe harmonic loads $m^{\mathrm{H}}$, which are derived from constant and periodic loads that arise due to steady wind loading, wind shear, and turbine self-weight. These harmonic loads can be mapped, or transformed, into estimates $m^{\text {Est }}$ of design loads $m^{\text {DLC }}$ that are computed using operational DLC simulations in Sect. 6. The key simplification of the harmonic load model compared to design loads computed using DLC simulations is the omission of load variations that occur at frequencies that do not correspond to the rotor speed. These non-harmonic load variations arise because of wind speed and direction changes, as well as the component's natural frequencies. All frequency components of a load are required to determine the design load for a final, detailed design, but for exploring potentially large numbers of design trade-offs, simplified harmonic loads provide enough information about the various turbine loads.

The harmonic loads are derived from FAST simulations with a sheared wind inflow such that the wind speed $u$ at height $z$ is

$u(z)=u_{\mathrm{h}}\left(\frac{z}{z_{\mathrm{h}}}\right)^{\alpha}$,

where $z_{\mathrm{h}}$ is the hub height, $u_{\mathrm{h}}$ is the wind speed at hub height, and $\alpha=0.14$, which is representative of an offshore wind field (Jenkins et al., 2001). Because of the wind shear, the turbine's structural load signals contain harmonic components that depend on the rotor azimuth $\psi$; i.e., a load signal $m(\psi)$ can be expressed as

$$
\begin{aligned}
m(\psi) & =m_{0}+m_{\mathrm{c}}^{1 \mathrm{P}} \cos (\psi)+m_{\mathrm{s}}^{1 \mathrm{P}} \sin (\psi)+\ldots \\
& +m_{\mathrm{c}}^{i \mathrm{P}} \cos (i \psi)+m_{\mathrm{s}}^{i \mathrm{P}} \sin (i \psi)+\ldots
\end{aligned}
$$



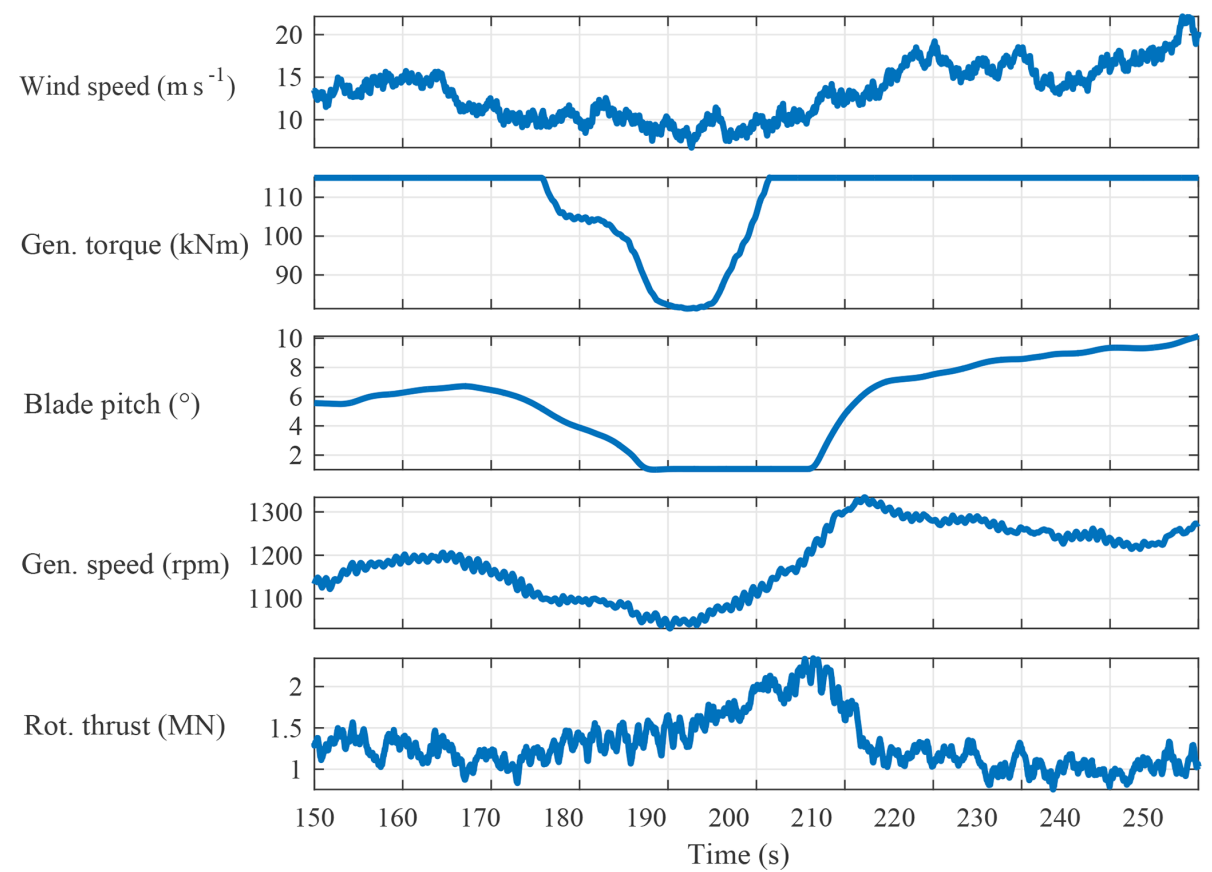

Figure 3. Baseline control illustration of a problematic gust for the SUMR-13A baseline rotor in extreme turbulence (DLC 1.3) with a mean wind speed of $14 \mathrm{~ms}^{-1}$. The peak rotor thrust near $205 \mathrm{~s}$ causes the peak blade flapwise load for the SUMR-13A.

The components are computed by

$m_{0}=\frac{1}{2 \pi N_{\mathrm{R}}} \int_{\psi-2 \pi N_{\mathrm{R}}}^{\psi} m(\psi) \mathrm{d} \psi$,

$m_{\mathrm{c}}^{i \mathrm{P}}=\frac{1}{\pi N_{\mathrm{R}}} \int_{\psi-2 \pi N_{\mathrm{R}}}^{\psi} m(\psi) \cos (i \psi) \mathrm{d} \psi$,

and

$m_{\mathrm{s}}^{i \mathrm{P}}=\frac{1}{\pi N_{\mathrm{R}}} \int_{\psi-2 \pi N_{\mathrm{R}}}^{\psi} m(\psi) \sin (i \psi) \mathrm{d} \psi$,

where $N_{\mathrm{R}}$ is the number of rotations used in the calculation (Phillips et al., 2007). We have found that load signals can be reconstructed closely using the first four harmonics; the most energy is usually in either the first, second, or third harmonic depending on the component (see Table 2) and number of blades.

From the components in Eqs. (5) and (6), the magnitude and phase of each harmonic can be computed:

$\left|m^{i \mathrm{P}}\right|=\sqrt{\left(m_{\mathrm{c}}^{i \mathrm{P}}\right)^{2}+\left(m_{\mathrm{s}}^{i \mathrm{P}}\right)^{2}}$,

and

$\phi^{i \mathrm{P}}=\tan ^{-1}\left(\frac{m_{\mathrm{s}}^{i \mathrm{P}}}{m_{\mathrm{c}}^{i \mathrm{P}}}\right)$.
An example for the blade flapwise load is shown in Fig. 4; most of the load magnitude is in the constant $m^{0}$ and onceper-revolution $m^{1 \mathrm{P}}$ load component $\left(10^{1}-10^{2} \mathrm{MNm}\right)$, with some in the $2 \mathrm{P}$ load component due to shaft tilt and gravity $\left(\sim 10^{0} \mathrm{MNm}\right)$, and very little in the higher harmonics $\left(<10^{-1} \mathrm{MNm}\right)$. We will use these harmonic coefficients, calculated via Eqs. (4)-(8), to estimate fatigue and extreme loads for the various wind turbine components.

\subsection{Extreme and fatigue loads}

The forces and moments on a component drive its design: larger loads require greater reinforcement, leading to greater component mass and cost. We analyze component loads in terms of the maximum (or peak) load:

$m_{\text {Peak }}^{\mathrm{H}}=\max _{u \in U}\left(m^{0}+m^{n \mathrm{P}}\right)$,

where $n$ is the dominant harmonic signal component and $U$ is the set of constant, sheared wind inputs used to derive the harmonic load. We perform simulations from cut-in to cutout (Table 1) in $0.5 \mathrm{~ms}^{-1}$ increments.

Fatigue loads are computed in terms of the damage equivalent load (DEL): the constant amplitude of a sinusoidal load signal that results in the same total accumulated damage from a more complex load signal. The accumulated damage in simulations with different wind speeds is extrapolated over the turbine lifetime using the wind speed probability distribution $p(u)$, characterized by the Weibull distribution in Ta- 

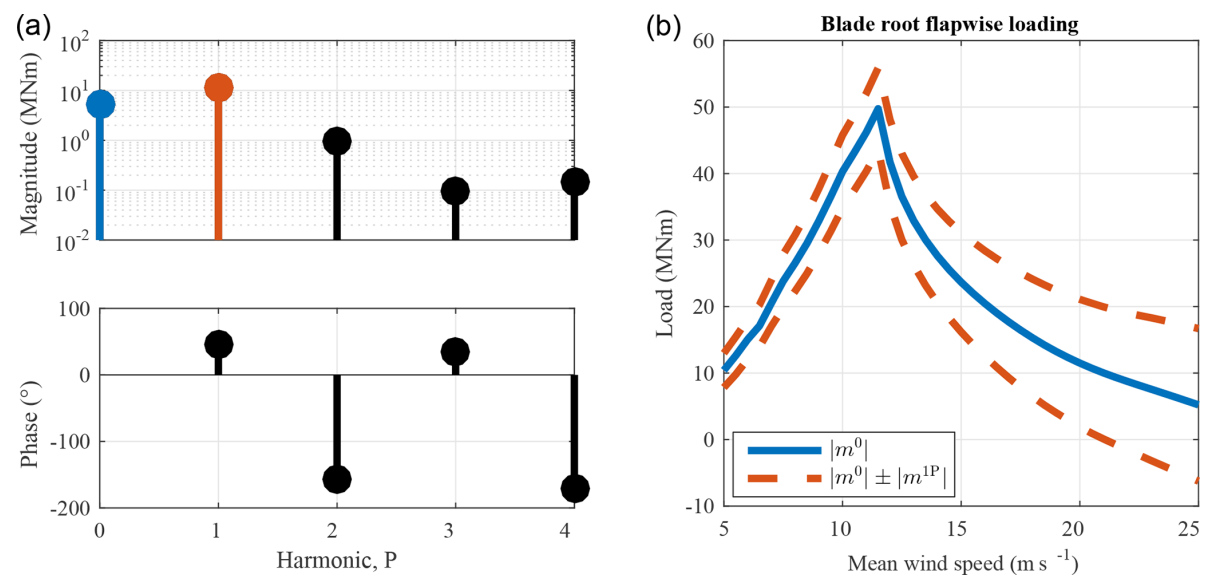

Figure 4. Load harmonic magnitude $\left|m^{i \mathrm{P}}\right|$ and phase $\phi^{i \mathrm{P}}$ for the zeroth through fourth periodic harmonic of the blade root load in the flapwise direction (a) of the SUMR-13A at $25 \mathrm{~ms}^{-1}$. Mean load (blue) superimposed with the $1 \mathrm{P}$ harmonic amplitude (red) with respect to wind speed (b) used to estimate fatigue and extreme loads.

Table 2. Structural loads evaluated in this article. Each component has loads in multiple directions and experiences the peak load and greatest contribution to fatigue loads at different wind speeds. $N_{\mathrm{B}}$ denotes the number of blades on the rotor. Loads that are nearly constant across wind speeds do not have a defined peak wind speed (N/A). The dominant wind speed contributing to fatigue is determined by analyzing the relative fatigue contribution, $p(u) m^{n \mathrm{P}}$ from Eq. (10), across wind speeds.

\begin{tabular}{llrlll}
\hline Component & $\begin{array}{l}\text { Dominant } \\
\text { harmonic }\end{array}$ & $\begin{array}{l}\text { Wöhler } \\
\text { exponent }\end{array}$ & $\begin{array}{l}\text { Load direction, } \\
\text { name }\end{array}$ & $\begin{array}{l}\text { Wind speed } \\
\text { at peak load }\end{array}$ & $\begin{array}{l}\text { Dominant wind speed } \\
\text { contributing to fatigue load }\end{array}$ \\
\hline Blade & $1 \mathrm{P}$ & $\begin{array}{l}\text { Flapwise, } m_{\mathrm{b} y} \\
\text { Edgewise, } m_{\mathrm{b} x}\end{array}$ & $\begin{array}{l}\text { Rated } \\
\text { N/A }\end{array}$ & $\begin{array}{l}\text { Rated } \\
\text { Below rated }\end{array}$ \\
\hline Hub & $1 \mathrm{P}$ & 3 & $\begin{array}{l}\text { Tilt, } m_{\mathrm{h} y} \\
\text { Yaw, } m_{\mathrm{h} z}\end{array}$ & $\begin{array}{l}\text { N/A } \\
\text { N/A }\end{array}$ & $\begin{array}{l}\text { Rated } \\
\text { Rated }\end{array}$ \\
\hline $\begin{array}{l}\text { Main bearing } \\
\text { (non-rotating) }\end{array}$ & $N_{\mathrm{B}} \mathrm{P}$ & 3 & $\begin{array}{l}\text { Tilt, } m_{\mathrm{s} y} \\
\text { Yaw, } m_{\mathrm{s} z}\end{array}$ & $\begin{array}{l}\text { Rated/cut-out } \\
\text { Rated/cut-out }\end{array}$ & $\begin{array}{l}\text { Rated } \\
\text { rated }\end{array}$ \\
\hline Yaw bearing & $N_{\mathrm{B}} \mathrm{P}$ & 3 & $\begin{array}{l}\text { Tilt, } m_{\mathrm{y} y} \\
\text { Yaw, } m_{\mathrm{y} z}\end{array}$ & $\begin{array}{l}\text { Rated/cut-out } \\
\text { Rated/cut-out }\end{array}$ & $\begin{array}{l}\text { Rated } \\
\text { Rated }\end{array}$ \\
\hline Tower & \multirow{2}{*}{$N_{\mathrm{B}} \mathrm{P}$} & 3 & $\begin{array}{l}\text { Fore-aft, } m_{\mathrm{t} y} \\
\text { Side to side, } m_{\mathrm{t} x}\end{array}$ & $\begin{array}{l}\text { Rated } \\
\text { Tower natural freq./cut-out }\end{array}$ & $\begin{array}{l}\text { Tower natural freq. } \\
\text { Tower natural freq. }\end{array}$ \\
\hline
\end{tabular}

N/A indicates "not applicable".

ble 1. We can relate the DEL of a component to its load harmonic by

$m_{\mathrm{DEL}}^{\mathrm{H}}=a_{\mathrm{DEL}}(n, w) \sum_{u \in U} p(u) m^{n \mathrm{P}}$,

where $a_{\mathrm{DEL}}$ is a tuning factor that depends on the Wöhler exponent $w$ and the dominant harmonic component $n$. The dominant load harmonic $n \mathrm{P}$ of each component is either $1 \mathrm{P}$ or $N_{\mathrm{B}} \mathrm{P}$, specified in Table 2, depending on whether the component is rotating $(1 \mathrm{P})$ or non-rotating $\left(N_{\mathrm{B}} \mathrm{P}\right)$. Different load harmonics will be specified by their location, direction, and harmonic number; e.g., the 3P main-bearing load about the $y_{\mathrm{s}}$ axis will be written $m_{\mathrm{s} y}^{3 \mathrm{P}}$. In this article, we focus on the moments about the load axes specified in Table 2 and illustrated in Fig. 5. The loads at higher harmonic and natural frequencies contribute to both fatigue and extreme loads, but since our goal is to derive a mapping from a simplified computation (harmonic load) to a more expensive simulation (design load), their effects are neglected and considered as part of the uncertainty of the transformation in Sect. 6.

\subsection{Harmonic versus turbulent loads}

The structural loads on a wind turbine originate from constant and periodic effects, modeled by the harmonic load, as well as from dynamics due to turbulence, which are not necessarily correlated with the azimuthal position of the rotor and are not modeled in this transformation. In some cases, the effect of turbulence greatly outweighs the constant and periodic effects, but in all cases, the harmonic loads can be 


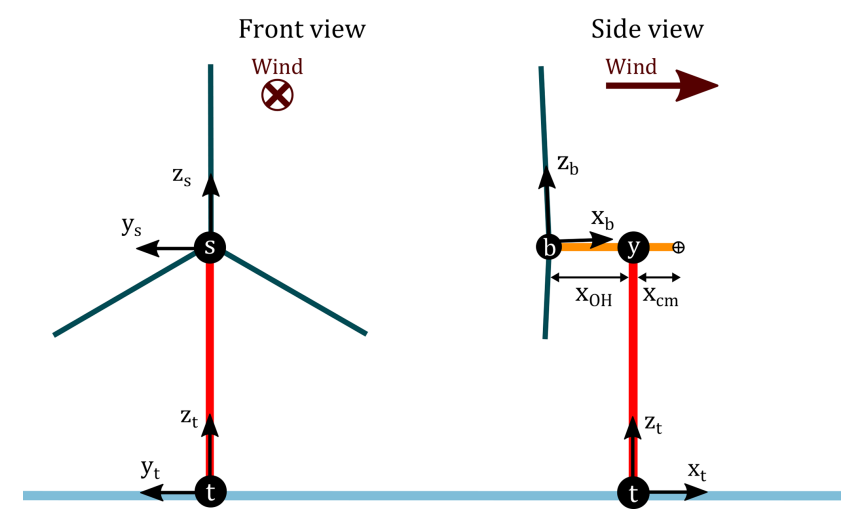

Figure 5. Illustration of the load axes used in this article. The nonrotating load axes - tower, main bearing, and yaw bearing - are all parallel and are denoted by subscripts "t", "s", and "y", respectively. Note: the blade, hub, and main-bearing axis origins are collocated; the blade and hub load axes rotate with azimuth angle, as shown in Fig. 12. The CONR-13 is depicted to illustrate the rotor overhang $x_{\mathrm{OH}}$ and nacelle center of mass $x_{\mathrm{cm}}$. The prevailing wind is positive in the same direction as the $x_{\mathrm{t}}$ axis.

mapped to the design loads determined by the DLCs. We quantify this relationship in Sect. 6 by mapping the harmonic loads, computed using Eqs. (9) and (10), to the design loads computed in DLC simulations. In Sects. 7-11, we present the design load estimates and their uncertainties, transformed from harmonic loads, as various turbine design choices are evaluated.

\section{Harmonic model transformation and uncertainty}

To balance the computational efficiency of the harmonic load estimation in Sect. 5 with the more expensive and realistic design loads computed using DLC simulations, we present the following transformation procedure. In this article, we focus on the moments on the turbine components during power-producing design load cases and simulate the following DLCs specified by the IEC standard (International Electrotechnical Commission, 2005):

- DLC 1.2: normal turbulence, for fatigue loads, using six random seeds at mean wind speeds from cut-in to cut-out, spaced $2 \mathrm{~ms}^{-1}$ apart.

- DLC 1.3: extreme turbulence, for peak loads, using the same number of turbulent wind seeds and wind speeds.

- DLC 1.4: extreme coherent gust with direction change, for peak loads near rated, above-, and below-rated wind conditions. Different rotor azimuthal initial conditions are simulated to account for the rotor being in different positions when the gust occurs.

- DLC 1.5: extreme wind shear, for peak loads near rated and at cut-out wind speeds. The same azimuthal initial conditions as in DLC 1.4 are used.
Fatigue loads are computed using the DLC 1.2 simulations in MLife (Hayman, 2012); they are extrapolated using the Weibull distribution in Table 1 to determine the lifetime DEL. The peak design load is determined using the maximum (moment) over all the simulations in DLCs 1.3-1.5.

First, we compare the harmonic loads, calculated using the methods in Sect. 5, with the loads computed in DLC simulations. Then, we present a method to map the harmonic loads to the design loads, producing load estimates. Finally, we analyze the residual of the estimated loads, since not all rotors in the design studies of Sects. 7-11 will be simulated using the DLCs. Only a subset of the rotors analyzed in this article, indicated in Table 3, are used in the following procedure to transform the harmonic model. The design loads of a freeteetering hinge will not be included in the transformation set and uncertainty analysis for reasons described in Sect. 9.2; it is marked with an "x" in Fig. 6.

In Fig. 6a, we show the design load for the peak mainbearing load versus the harmonic load estimate. In general, the harmonic load estimate is much less than the design load computed in DLC simulations. For each component, part of the load can be attributed to the harmonic loading and part to the turbulent loading:

$m^{\mathrm{DLC}}=m^{\mathrm{H}}+m^{\text {turb }}$.

We quantify the turbulent load contribution $m^{\text {turb }}$ of each component load using the turbulence factor

$f^{\text {turb }}=\frac{\text { mean }\left(m^{\text {turb }}\right)}{\text { mean }\left(m^{\text {DLC }}\right)}$

to compare between different turbine parts on how much of the design load $m^{\text {DLC }}$ is attributed to turbulent versus harmonic loading for Class IIB turbulence.

For example, all peak main-bearing loads found using DLC simulations are shown in Fig. 6a, b. The average design load $\left(m^{\text {DLC }}\right)$ of the three-bladed peak main-bearing loads (magenta) in Fig. 6a is approximately $40 \mathrm{MNm}$, while the average of the corresponding harmonic loads $\left(m^{\mathrm{H}}\right)$ is approximately $10 \mathrm{MNm}$. Thus, the average turbulent load ( $\left.\mathrm{m}^{\text {turb }}\right)$ is approximately $30 \mathrm{MNm}$ by Eq. (11). Thus, using Eq. (12), $f^{\text {turb }} \approx 0.75$, as shown in Fig. $6 \mathrm{c}$, along with a selection of the other turbine loads. Some loads, like the edgewise (blade X) DEL and the hub DEL about the $z_{\mathrm{h}}$ axis for twobladed rotors, are better represented by the harmonic model, as indicated by lower turbulence factors compared with the others. In general, peak loads are better represented by the harmonic load than DELs and rotating component loads are better represented by the harmonic model than non-rotating component loads. Peak loads, defined both by the harmonic model and in turbulent simulations, depend to a large extent on the constant or mean wind speed, respectively, which is represented with the same value in both cases. On the other hand, wind speed changes have a large effect on the fatigue DELs, which is not modeled by the harmonic load. 

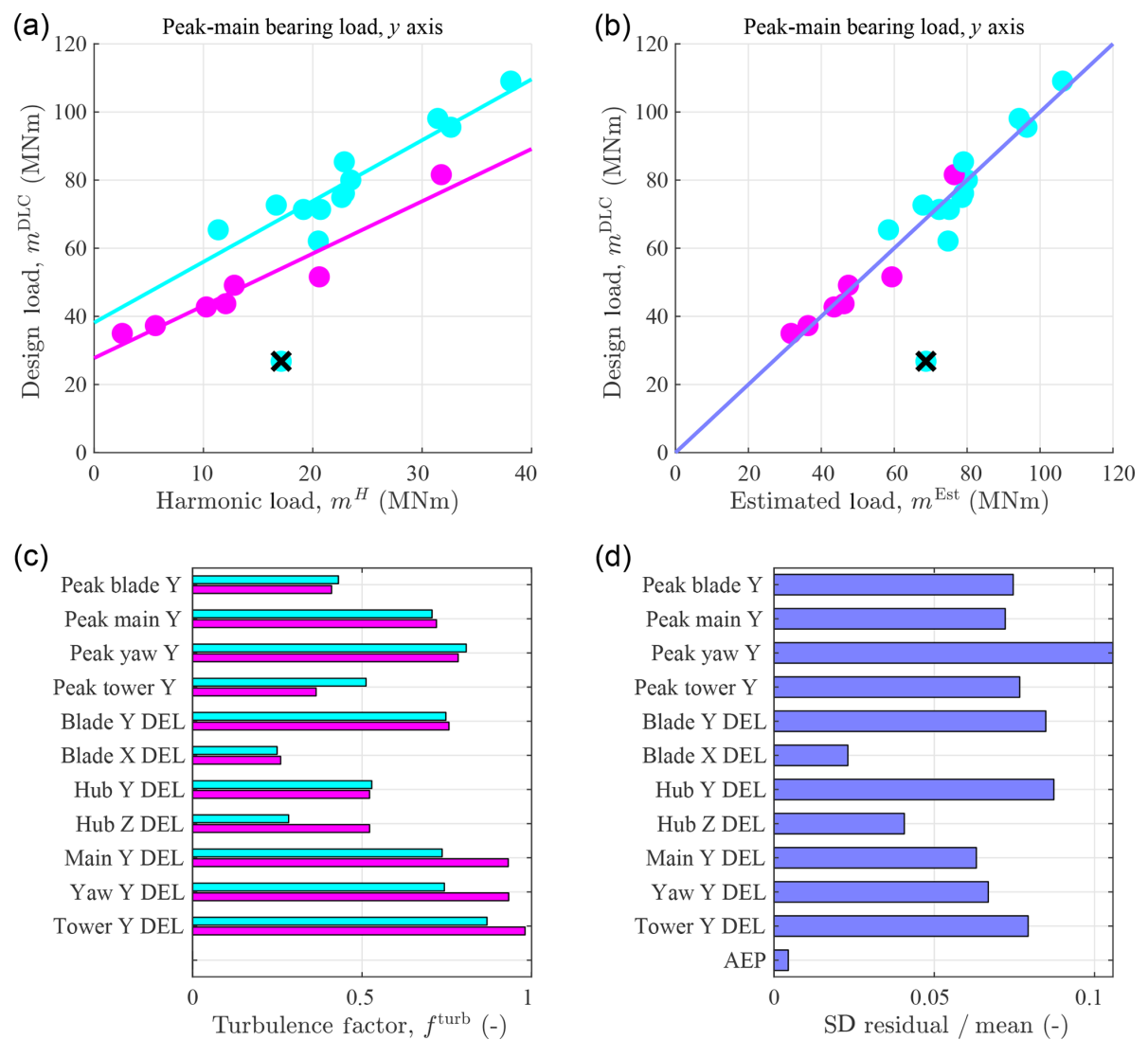

Figure 6. Peak main-bearing loads computed using DLC simulations versus the harmonic load (a) and transformed load estimates (b) for two-bladed rotors (cyan) and three-bladed rotors (magenta). The same color scheme is used to show the relative effect of turbulence on selected component loads (c), as defined in Eq. (12), and the standard deviation of the residual normalized by the mean load is shown for the whole transformation set (d). The loads presented in this study are specifically the moments about the specified axis.

Rotating component loads in turbulence are primarily driven by the 1P load, which is more clearly modeled by the harmonic loads, due to gravity and wind shear, than the smaller $N_{\mathrm{B}} \mathrm{P}$ load component.

We also see a difference in how turbulence affects twoversus three-bladed rotors, illustrated by the different lines of fit in Fig. 6a. In general, two-bladed rotors have a greater turbulent load component, but they also have a larger harmonic component, so the turbulence factor is similar to three-bladed rotors. For three-bladed rotors, the non-rotating load component DELs are not clearly modeled by their harmonic load, so they have a relatively high turbulence factor. Even though some turbine parts have large turbulent components that are not directly modeled by their harmonic loads, there is still good correlation between the harmonic and design loads.

We transform from the harmonic loads to the design loads by fitting a linear model,

$m^{\text {DLC }}=a^{\text {trans }} m^{\mathrm{H}}+b^{\text {trans }}$,

and finding the linear least squares estimate of the parameters $a^{\text {trans }}$ and $b^{\text {trans }}$. Because two- and three-bladed rotors sample turbulence differently, we define a transformation set
( $a^{\text {trans }}, b^{\text {trans }}$ ) separately for each, illustrated by the different fits of Fig. 6a. There are also different transformation sets for each design load: at each axis and for both peak and fatigue loads. To estimate the design load, the transformation set corresponding to the desired component, axis, and number of blades is used:

$m^{\text {Est }}=a^{\text {trans }} m^{\mathrm{H}}+b^{\text {trans }}$,

which results in a transformed load estimate equal to the design load, plus some residual (Fig. 6b).

We analyze the uncertainty of the transformation by computing the residuals between the estimated loads, which are fit using the linear relation (Eq. 14), and design loads of the set of rotors specified in Table 3. In Fig. 6d, we normalize the standard deviation of the residual by the mean load over all rotors to use a qualitative metric comparing the fit of the transformation across different turbine parts. We present the standard deviation of the residual without this normalization for each measure in the figures of Sects. 7-11.

In general, the standard deviation of the residual is less than $12 \%$ of the mean value, which indicates decent agreement between the transformed load estimates and the DLC- 
Table 3. Set of turbines designed and analyzed in this article. ${ }^{a}$ denotes a turbine for which DLC simulations were performed and used to map the harmonic load estimates to DLC-based design loads. Otherwise, only the harmonic load analysis is performed. $\mathrm{b}$ was omitted from the transformation set. ${ }^{\mathrm{c}}$ denotes the SUMR$13 \mathrm{~A}$ rotor and ${ }^{\mathrm{d}}$ denotes a three-bladed variation of the SUMR-13A rotor. The process for using axial induction as an independent design variable will be described in the rotor aerodynamic trade studies section (Sect. 8.1).

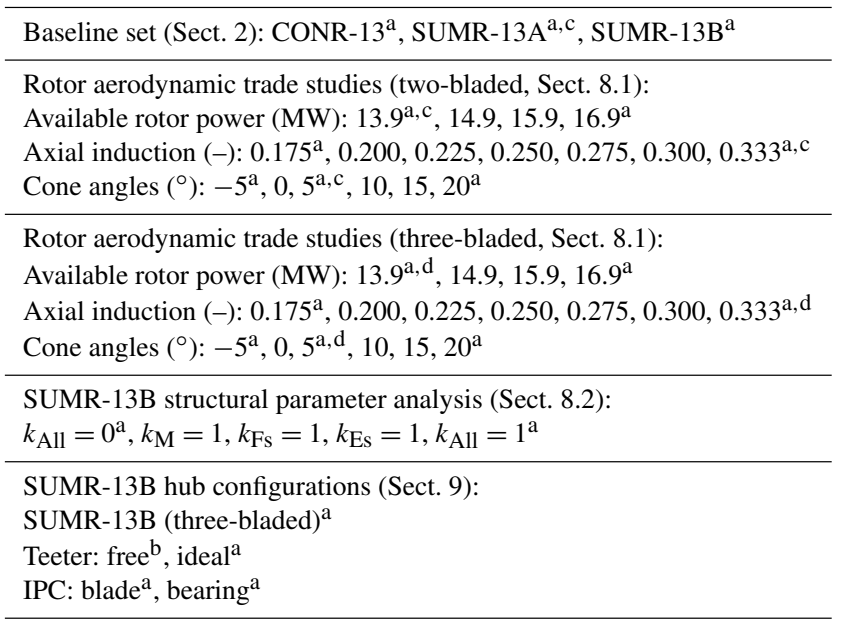

computed design loads. The cases with lowest uncertainty tend to have lower turbulence factors, like the blade edgewise (blade $\mathrm{X}$ ) DEL and the hub $z_{\mathrm{h}}$-axis DEL. The AEP is also very well estimated by the harmonic model, which is good for power capture predictions as long as the effects of turbulence are transformed.

The most erroneous load component is the peak yawbearing load about the $y_{\mathrm{y}}$ axis, which has a large turbulent component and where a subset of the transformation set (the aerodynamic trade study designs) controls a problematic gust event, like the one in Fig. 3, similarly. These rotors have design loads that are about the same for each, despite the differences predicted by the harmonic model. The design loads for this component might be more a function of the gust event than the turbine configuration.

In the remainder of this article, we use these mapped load estimates to analyze the structural loading and power capture of the various rotor configurations in Table 3 .

\section{Overview of design studies}

In this section, we outline the design and simulation results of the 42 turbines shown in Table 3. The design loads for each rotor are estimated using harmonic loads from Sect. 5 and the transformation method in Sect. 6. Additionally, gross AEP is calculated using the generator power $P(u)$ at mean wind speed $u$ by

$\mathrm{AEP}=8760 \sum_{u \in U} p(u) P(u)$, where $p(u)$ is the Weibull distribution in Table 1 and 8760 is the number of hours in a year.

We first examine changes to the blade loads and power capture of the SUMR-13A due to variations in the aerodynamics, including the blade length, axial induction, and cone angles. Both upwind (negative) and downwind (positive) cone angles are evaluated. The aerodynamic changes lead to a larger, heavier but more powerful SUMR-13B rotor, which we use to study the effect of mass and stiffness scaling on blade loads. Next, non-rotating component loads will be compared for different hub configurations, considering the number of blades, a teetering hinge, individual pitch control, and rotor placement (upwind versus downwind). Finally, the effect of a downwind rotor on yaw-bearing design loads will be presented and the effect of a two-bladed rotor on tower design will be investigated. A summary of the design parameters considered in this article and the process for incorporating their interconnections is shown in Fig. 7; details are given in Sects. 8-11.

\section{Blade loads and energy capture}

We begin by analyzing the effect of changing rotor aerodynamics on blade loads and energy capture. Blade loads are computed at the blade root in both the flapwise $\left(m_{\mathrm{b} y}\right)$ and edgewise $\left(m_{\mathrm{b} x}\right)$ directions. Blade flapwise loads are primarily aerodynamic in nature and depend on the thrust force exerted on the blades from the wind inflow. Peak blade flapwise loads occur near rated wind speed, which represents the worst combination of wind speed and orthogonal blade surface area but before the blade begins pitching to regulate power in the above-rated operation. Blade pitch has a significant influence on the mean blade flapwise load and control actions can often cause peak loads, e.g., when the pitch angle decreases towards its fine pitch angle to maximize power and then a wind speed gust occurs. The dependence of this load on the control system highlights the necessity of including control design at an early stage.

Flapwise fatigue loads are driven by blade thrust, wind shear, and, to a small degree, blade weight and cone angle. Edgewise fatigue loads, on the other hand, have a nearly constant load cycle amplitude, unless the rotor torque is rapidly changing. The load cycle amplitude of edgewise blade loads depends on the blade weight, creating a large positive and then negative load when the blade is in each horizontal position during a rotor revolution. Edgewise fatigue loads increase with blade length and mass and influence the design of the baseline blade structures used in this study (CONR13, SUMR-13A). Additional stiffness must compensate for increased edgewise loads but at the cost of increased blade mass, leading to even greater loads. We will explore this relationship in Sect. 8.2.1. 


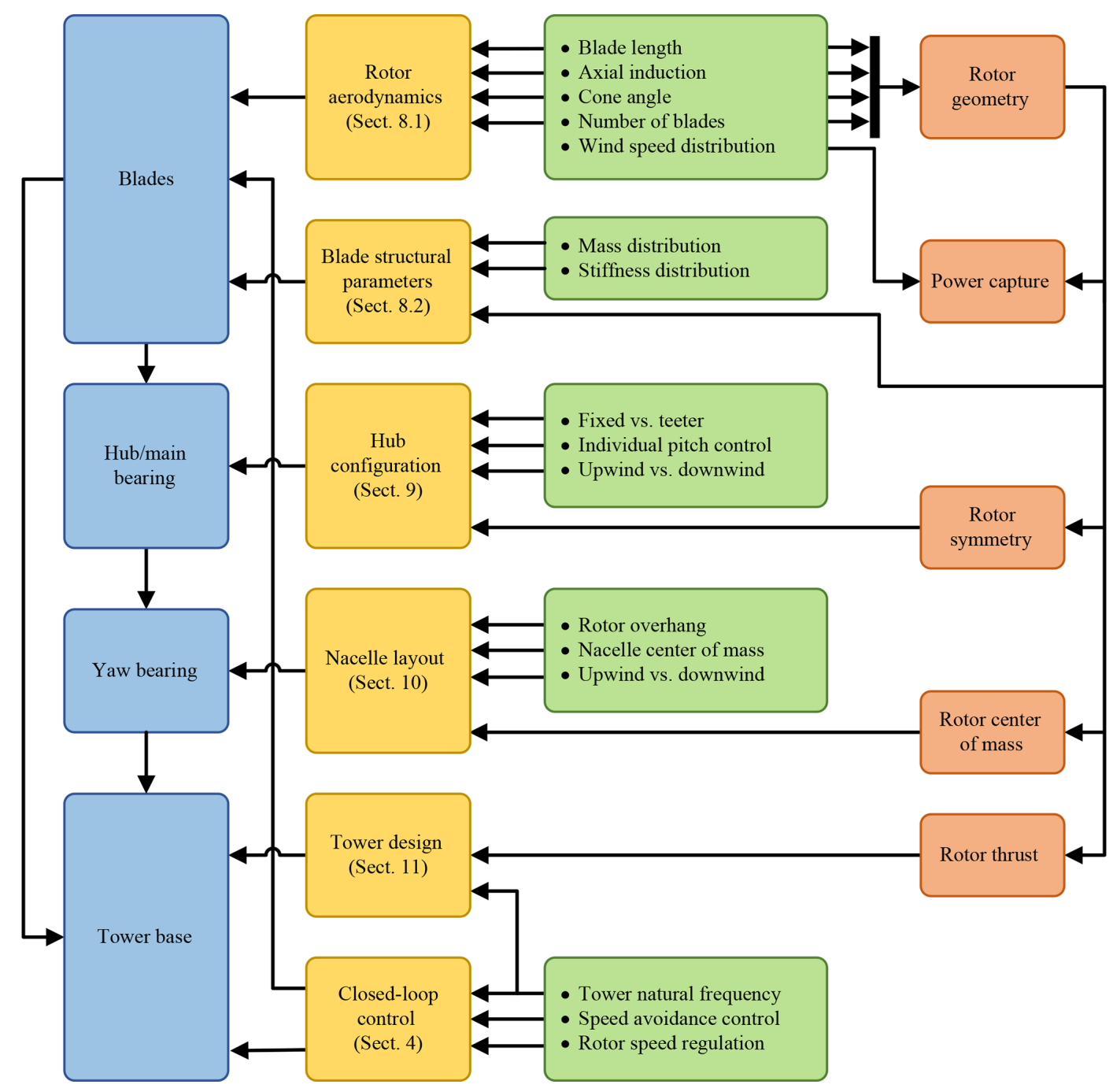

Figure 7. Overview of the design studies performed in this paper. The loads on each component (blue) transfer from the blades to the tower base as shown. Design studies (yellow) that affect each component are performed in Sects. 8-11 by altering the design parameters in green. Rotor design parameters (orange) affect all aspects of turbine design.

\subsection{Rotor aerodynamics}

We evaluate rotors with longer blade lengths, lower axial induction factors, and large, downwind cone angles, using the SUMR-13A design described in Sect. 2 as a baseline. These design studies have led us to an updated, larger, two-bladed design, indicative of the trends in industry towards longer, more slender blades but with a greater downwind cone angle. We will call this new rotor SUMR-13B (see Table 1 for more details).

Blade length is changed indirectly in PROPID by increasing the available rotor power at $11.3 \mathrm{~ms}^{-1}$ from 13.9 to 16.9 MW. However, all rotors are controlled to have the same rated generator power of $13.2 \mathrm{MW}$, which limits the increase in peak blade loads by transitioning to above-rated control at lower wind speeds. ${ }^{1}$ The increased rotor-swept area increases both power capture and blade loads; a $10 \%$ increase in rotor radius results in about a $10 \%$ increase in AEP and $15 \%$ increase in peak blade flapwise load (blue, left column in Fig. 8). For the blade length design study, the axial induction factor along the outer three-fourths of the blade is fixed at $\frac{1}{3}$ (theoretical Betz limit).

The rotors used to evaluate axial induction (red, center column in Fig. 8) are designed by fixing the flapwise root bending loads to that of the SUMR-13A and fixing the available rotor power at rated wind speed to 13.9 MW. The blade length, chord, and twist are allowed to vary as the local axial induction factor - from the $25 \%$ radial location to the blade

\footnotetext{
${ }^{1}$ The available rotor power of $13.9 \mathrm{MW}$ at $11.3 \mathrm{~ms}^{-1}$ and rated generator power of $13.2 \mathrm{MW}$ correspond to a $95 \%$ generator efficiency.
} 

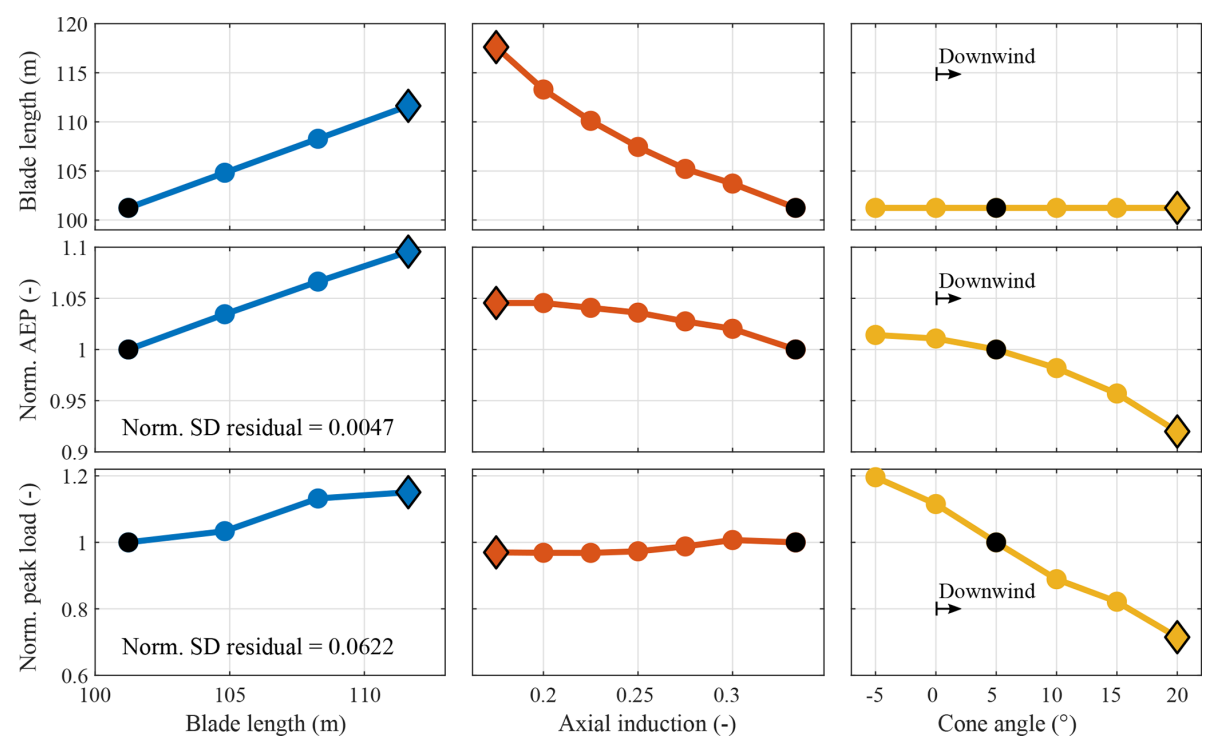

Figure 8. Summary of aerodynamic design studies: the blade length, axial induction (in combination with blade length, chord, and twist), and cone angle are varied, while the AEP and peak blade load are calculated and compared to the base case (SUMR-13A, black dot in all). The standard deviations of the residuals for AEP and peak flapwise load are normalized to the SUMR-13A values and apply across all design studies. All rotors here are two-bladed, and positive cone angles correspond to downwind rotors. Unless otherwise specified, the available rotor power is $13.9 \mathrm{MW}$, the axial induction is 0.333 , and the cone angle is $5^{\circ}$.

tip - varies from 0.175 to 0.3 in increments of 0.025 . Decreasing the designed axial induction of the rotor results in longer, more slender blades that capture more energy while constraining blade loads. In the most extreme example, a blade with a 0.175 axial induction factor can increase the AEP by $5 \%$, compared to a rotor with aerodynamically optimal blades (axial induction factor of $\frac{1}{3}$ ) but requires $16 \%$ longer blades.

The cone angle design study is performed using the same baseline SUMR-13A blades for each rotor but with different cone angles, including upwind (negative) and downwind (positive) cone angles. With a fixed blade length, downwind, highly coned rotors decrease the rotor-swept area, resulting in both reduced power capture and blade loads. The load decrease is significant: $25 \%$ compared with a $7 \%$ decrease in power capture. In comparison with the blade length design study, it is clear why highly coned rotors are attractive for large rotor designs: an increased cone angle will decrease operational loads faster than an increase in blade length will increase them.

For all the aerodynamic design studies, there is a trade-off between power capture and blade loading. Each design study is plotted together in Fig. 9, which also indicates the DELs in the flapwise and edgewise directions. In rotor design, our goal is to increase AEP and decrease blade loads, thus aiming to yield results in the lower right quadrant of each plot.

The SUMR-13A blade design was found to be driven by extreme loading along a combined flapwise and edgewise direction, where DLC 1.4 (extreme coherent gust with direction change) caused the greatest blade load. Since edge- wise loads are largely deterministic, varying with a nearconstant amplitude with respect to the rotor azimuth, the design goal of the next rotor iteration, the SUMR-13B, was to constrain peak flapwise loads and increase power capture using the aerodynamic design changes previously described. The SUMR-13B is not necessarily cost optimal. Using larger blades with both greater power capture and structural loading could potentially result in a net cost benefit compared to the SUMR-13B. However, in the absence of a detailed cost model, these design choices are difficult to make and depend on a wide array of factors. Larger rotors with both increased loading and power capture will be investigated in future design iterations.

The SUMR-13B does, however, provide a demonstration for using the harmonic loads and results in Fig. 9 to guide design: the aerodynamic design changes can be applied in combination. Since the goal of the SUMR-13B is to constrain peak flapwise loads and increase power capture (AEP), some combination of increasing the blade length, decreasing the axial induction, and increasing the cone angle should provide a blade with the desired properties. Looking at the peak flapwise blade load (leftmost in Fig. 9), if we start at the SUMR-13A, the black dot at $(1,1)$, and increase the available rotor power to $16.9 \mathrm{MW}$, we will have a rotor with the relative power and load at the blue diamond. Then, if we decrease the axial induction to 0.2 , the change in power and load is as if only the axial induction (and corresponding blade length increase) were changed by that amount (dashed red vector). Finally, by increasing the cone angle from 5 to $12.5^{\circ}$, the change in power and load is equivalent to the change 


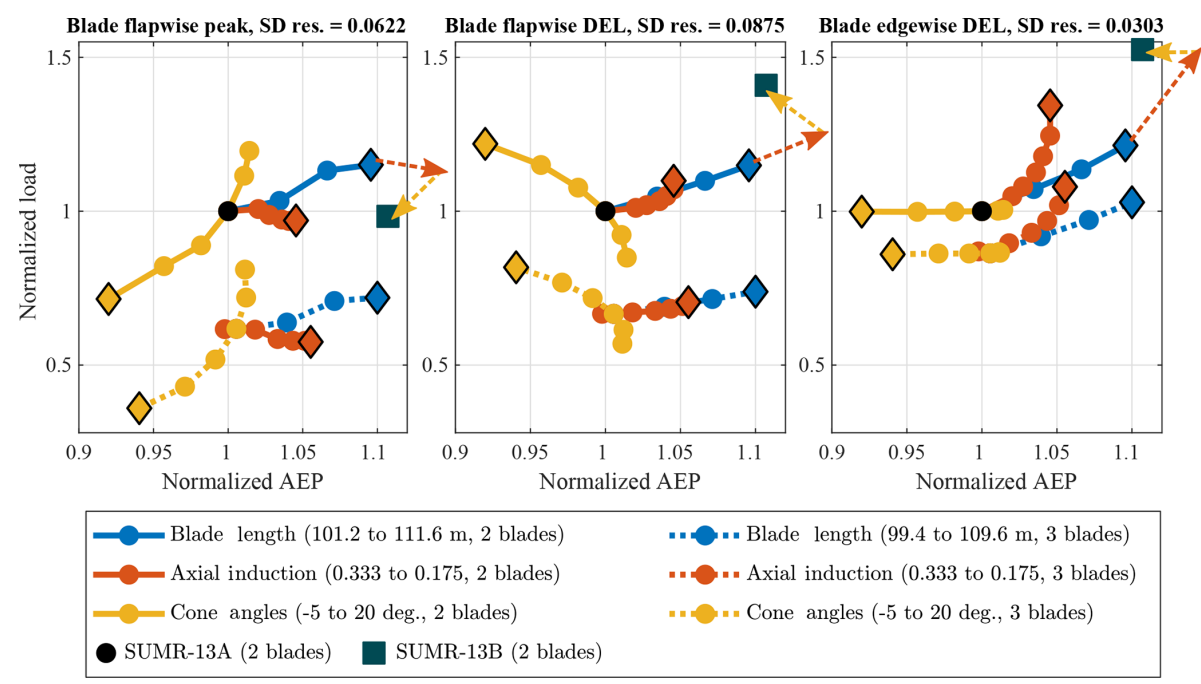

Figure 9. The trade-off between power capture and blade loads. The AEP is plotted on the $x$ axis and blade loads are plotted on the $y$ axis. All rotors are normalized to the two-bladed 101.2 m SUMR-13A baseline rotor design (black dot). Each dot represents a rotor design and each curve represents the variation of one design parameter. The set of three-bladed rotor designs is represented with dotted curves. Unless otherwise specified, the available rotor power is $13.9 \mathrm{MW}$, the axial induction is $\frac{1}{3}$, and the cone angle is $5^{\circ}$; the SUMR-13B is specified in Table 1. The normalized residual standard deviation for AEP is the same as in Fig. 8, and the load residual standard deviations are normalized to the corresponding SUMR-13A values. The vectors indicate design changes in combination: blade length increase (blue diamond), axial induction factor decrease along with corresponding blade length increase (red, dashed vector), and cone angle increase (yellow, dashed vector) from the SUMR-13A to the SUMR-13B (square).

indicated by the dashed yellow vector. The combination of these design changes results in the AEP and structural loading of the SUMR-13B: it increases AEP by $11 \%$ compared to the SUMR-13A while constraining peak blade flapwise loads to the level of the SUMR-13A. The same changes can be applied in combination to the flapwise DELs and edgewise DELs. The increased blade length of the SUMR-13B increases the flapwise DELs due to the enhanced effect of wind shear and edgewise DELs due to the additional blade weight. During the SUMR-13B structural lay-up design, we found the design driving blade load to be the fatigue DEL in the edgewise direction, which will be the focus of Sect. 8.2.1.

A set of three-bladed rotors (shown with dotted lines in Fig. 9) is designed similarly to the two-bladed design studies and exhibit similar trends to the two-bladed rotors in terms of blade loads. The blades of the three-bladed rotors experience lower loads (both peak and fatigue, edgewise and flapwise) with the same power capture due to their smaller chord and mass.

Despite the larger blade loads on two-bladed rotors compared to three-bladed rotors with the same power capture, we will be analyzing the two-bladed SUMR-13B for the remainder of this article. When comparing similarly powered rotors, e.g., the CONR-13 and the SUMR-13A, two-bladed rotors reduce the total blade mass by as much as $25 \%$, which reduces the capital expenditures associated with blade material costs (Griffith, 2017). Given the constant AEP and decrease in CapEx of the two-bladed rotors, we would expect the overall COE of a two-bladed rotor to be less than that of a similarly powered three-bladed rotor. However, periodic effects are more pronounced on the non-rotating components of two-bladed rotors. We will analyze the load-alleviating potential of different hub configurations in Sect. 9 and structural reinforcement in Sect. 8.2.

\subsection{Blade structural parameters}

As a wind turbine blade increases in length, its mass and stiffness increase to account for the additional structural loading. The structural properties of a blade are described by its distributed parameters along the blade span, which include mass, stiffness, and inertia per unit length. In the previous section, these distributed structural parameters were constant for different blade lengths. In this section, we will change the distributed mass and stiffness values through various scaling rules to observe the effect each parameter has on the blade loads. However, changes to the mass and stiffness are not necessarily independent of each other. We will analyze the dependency between blade mass, stiffness, and load using the results of the initial parameter study to determine an initial guess for the distributed parameters of the SUMR-13B blade. The initial guess can then be used for the load simulations that are used to do a more detailed structural lay-up design and determine the final distributed structural parameters for the blade. 
To model blades with different lengths, we start with classical similarity scaling rules (Loth et al., 2017a), based on the length scaling factor:

$\eta=L / L_{0}$,

where $L$ is the length of the scaled blade and $L_{0}$ is the length of the original blade. In this study, $L_{0}$ is the length of the baseline blades: the SUMR-13A for two-bladed rotors and the CONR-13 for three-bladed rotors. We will examine the scaling of the following parameters (Griffith and Ashwill, 2011):

- mass per unit length, which scales with $\eta^{2}$;

- stiffness per unit length in the flapwise, edgewise, and torsional directions, which scales with $\eta^{4}$;

- stiffness per unit length in the spanwise direction, which scales with $\eta^{2}$; and

- inertia per unit length in the flapwise and edgewise directions, which scales with $\eta^{4}$.

Once integrated over the blade length, e.g., the mass scales with $\eta^{3}$, while the stiffness and inertia properties scale with $\eta^{5}$.

These parameters can be more flexibly scaled to account for innovations or changes to the structural design. For instance, we scale the mass per unit length distribution by

$M(r)=M_{0}(r) \eta^{2 k_{\mathrm{M}}}$,

where $M(r)$ is mass per unit length at spanwise location $r$ of the scaled blade, $M_{0}$ is the mass per unit length of the original blade, and $k_{\mathrm{M}}$ is a tunable parameter to increase or decrease the blade mass. Based on Eq. (17), once integrated over the blade length, $k_{\mathrm{M}}=0$ would produce a blade with a mass that scales linearly with blade length, while $k_{\mathrm{M}}=1$ would produce a blade with a mass that scales with the cube of blade length. State-of-the-art trends show that mass scales roughly with the square of blade length, or $k_{\mathrm{M}}=0.5$. A similar parameter can be defined for stiffness scaling:

$k_{\mathrm{s}, \text { flap }}=k_{\mathrm{s}, \text { flap }, 0} \eta^{4 k_{\mathrm{Fs}}}$,

where $k_{\mathrm{s} \text {,flap }}$ is the flapwise stiffness per unit length of the scaled blade, $k_{\mathrm{s}, \text { flap }, 0}$ is the flapwise stiffness per unit length of the original blade, and $k_{\mathrm{Fs}}$ is a tunable flapwise stiffness scaling parameter. The edgewise stiffness will be similarly scaled using a parameter $k_{\text {Es }}$. Flapwise and edgewise inertia is scaled using the same mass-scaling parameter $k_{\mathrm{M}}$ but to the fourth power as in Eq. (18). Torsional and spanwise stiffness is scaled according to the similarity scaling rules defined above, with $\eta^{4}$ and $\eta^{2}$, respectively. The SUMR-13B (two-bladed, $\eta=1.24$ ) structural properties are scaled from the SUMR-13A blade, first separately each for the mass and stiffness parameters, and then all together (full scaling) in Fig. 10.

Ultimately, the final structural parameters will be determined by the structural lay-up, but this model could be used to more quickly analyze trade-offs between blade mass, stiffness, loads, and power. In general, mass scaling has the greatest impact on loads. Since this article only considers operational load cases, the effect is most apparent when analyzing fatigue loading. Loads during shutdown events and fault cases are also expected to increase with blade mass. Increased flapwise stiffness contributes to a small increase in energy capture (about $1 \%$; not shown) due to decreased blade deflection. We also observe that the change in load due to each individual scaling parameter $\left(k_{\mathrm{M}}, k_{\mathrm{Fs}}\right.$, and $\left.k_{\mathrm{Es}}\right)$ approximately sum (or combine linearly), when multiple parameters are simultaneously scaled. This is shown in Fig. 10: the sum of the changes in load due to mass, flap. stff., and edge stff. is approximately equal to the change in load due to full scaling. The same is true for the final design, which is a combination of the scaling parameters that are determined in the next section.

\subsubsection{Selecting $k_{\mathrm{M}}$ and $k_{\mathrm{Es}}$ for edgewise fatigue loads}

The most significant impact of positive structural scaling is the increase in edgewise DELs due to the increased blade mass. Theoretically, the additional mass increase of the larger blade would provide additional reinforcement against these loads, through trailing edge reinforcement or increased root diameter. We see that changes to the blade mass result in a change in edgewise load $\delta m_{\mathrm{b} x}$, i.e.,

$\delta m_{\mathrm{b} x}=a_{1} k_{\mathrm{M}}+b_{1}$,

where $a_{1}$ and $b_{1}$ are determined from FAST simulations of the SUMR-13B blade with multiple $k_{\mathrm{M}}$ values from 0 to 1 by finding the linear relationship between $k_{\mathrm{M}}$ and $\delta m_{\mathrm{b} x}$. Additional edgewise stiffness must compensate for the increase in edgewise load by increasing the ultimate load:

$m_{\mathrm{ult}}=\frac{2 \sigma \mathrm{EI}_{x}}{c}$,

where $\sigma$ is the fiberglass strain limit at the trailing edge, $\mathrm{EI}_{x}$ is the edgewise stiffness, and $c$ is the blade chord; this is a simplification that assumes the neutral axis is at midchord (Budynas and Nisbett, 2015). In terms of the scaling coefficients, a linearized version of Eq. (20) can be obtained:

$k_{\mathrm{Es}}=a_{2} \delta m_{\mathrm{b} x}+b_{2}$.

Finally, changes to the blade structural lay-up in the form of trailing edge reinforcement to increase edgewise stiffness will increase the blade mass:

$k_{\mathrm{M}}=a_{3} k_{\mathrm{Es}}+b_{3}$, 

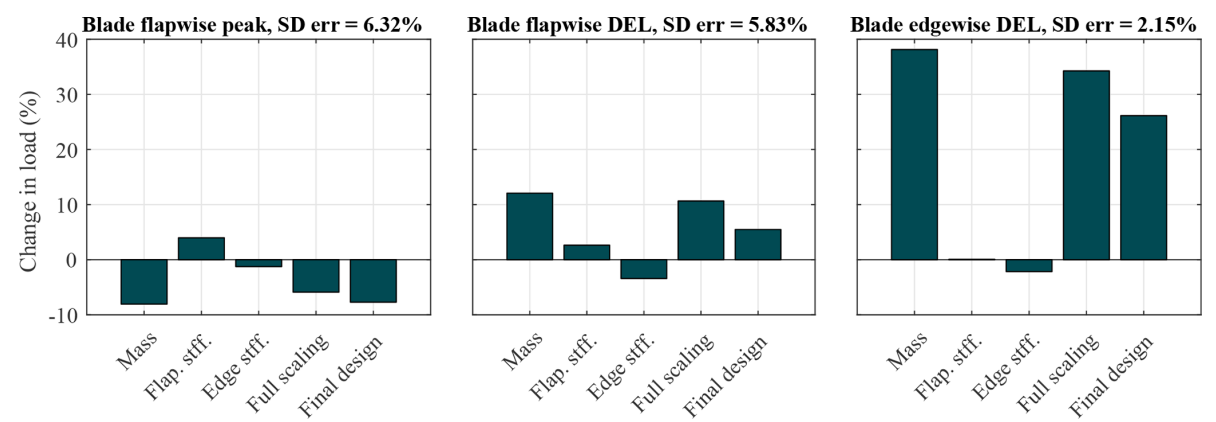

Figure 10. With $\eta=1.24$ and relative to the SUMR-13B with non-scaled structural parameters $\left(k_{\mathrm{M}}=k_{\mathrm{Fs}}=k_{\mathrm{Es}}=0\right.$, which yield the SUMR-13B loads in Fig. 9), these plots show the effect of independently scaling the mass $\left(k_{\mathrm{M}}=1\right)$, flapwise stiffness $\left(k_{\mathrm{Fs}}=1\right)$, and edgewise stiffness $\left(k_{\mathrm{Es}}=1\right)$, as well as the combined effect of scaling all of the structural parameters $\left(\right.$ Full $\left.\mathrm{Scaling}, k_{\mathrm{M}}=k_{\mathrm{Fs}}=k_{\mathrm{Es}}=1\right)$. The standard deviation of the residual is computed using the transformation set in Table 3 and is normalized to the non-scaled SUMR-13B.

Table 4. Blade structural coefficients for the SUMR-13B blade determined using the relationships described in Fig. 11.

\begin{tabular}{ll}
\hline Structural relations & Final design coefficients \\
\hline$a_{1}=0.51, b_{1}=1.40$ & $\delta m_{\mathrm{bx}}=1.8$ \\
$a_{2}=0.95, b_{2}=-0.79$ & $k_{\mathrm{Es}}=0.92$ \\
$a_{3}=0.87, b_{3}=0$ & $k_{\mathrm{M}}=0.804$ \\
\hline
\end{tabular}

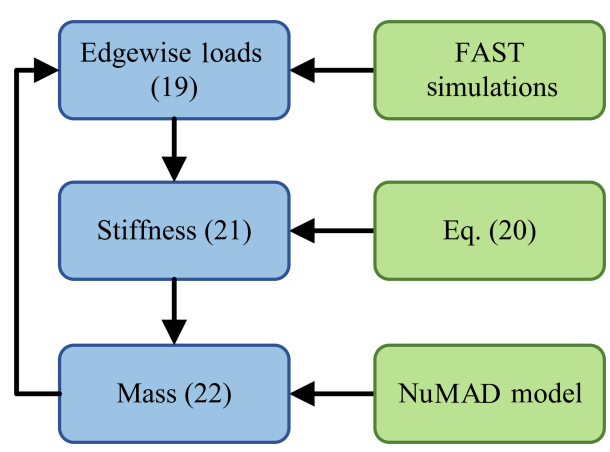

Figure 11. The relationship between blade mass, edgewise loads, and edgewise stiffness, as well how each value was derived.

where $a_{3}$ and $b_{3}$ are determined through a linear regression of SUMR-13B blade designs in NuMAD (Berg and Resor, 2012) with a target $k_{\mathrm{Es}}$ from 0 to 1 . Additional trailing edge reinforcement was applied to meet the target values within $5 \%$ and the $k_{\mathrm{M}}$ was computed using the overall mass of the resulting blade model.

The linear system determined by Eqs. (19), (21), and (22) can be solved to determine the necessary structural reinforcement for accommodating the load increase due to the increase in mass. See Table 4 for the results. These parameters can serve as targets for a detailed SUMR-13B structural lay-up design. For the remainder of this study, we will evaluate the loading on other components as a result of the mass increase shown in Table 4.

\section{Hub configuration and main-bearing loads}

Blade loads are transferred through the blade root to the hub at the pitch actuator. In this section, we analyze the load cycle amplitudes of the hub loads and how they transfer to the non-rotating turbine components. The hub load axes, $y_{\mathrm{h}}$ and $z_{\mathrm{h}}$, rotate with the hub (Fig. 12). About the $y_{\mathrm{h}}$ axis, hub loads are directly related to the blade loads for both two- and three-bladed configurations; they peak when the rotor is near $\psi=0^{\circ}$ due to vertical wind shear, resulting in a large cosinecyclic component of the hub load about the $y_{\mathrm{h}}$ axis $\left(m_{\mathrm{h} y, \mathrm{c}}^{1 \mathrm{P}}\right)$. A teeter hinge reduces the coupling between blade and hub loads, except in cases of very large rotor deflections, where "hard" end stops increase the coupling and result in large peak loads. About the $z_{\mathrm{h}}$ axis, the source of loading depends on whether the rotor has two or three blades (see Fig. 12). For three-bladed rotors, the hub load about the $z_{\mathrm{h}}$ axis is driven by the blade aerodynamic loading due to wind shear and has a similar magnitude to the load about the $y_{\mathrm{h}}$ axis (Fig. 12, top right). This symmetry is not inherent in a two-bladed configuration; the $m_{\mathrm{h} z}$ load is primarily determined by the weight of the blades unless there is a horizontal wind shear. The mismatch between the load cycle amplitudes of $m_{\mathrm{h} y}$ and $m_{\mathrm{h} z}$ results in larger non-rotating loads, e.g., $m_{\mathrm{s} y}$, for twobladed rotors (Fig. 12, bottom right). The hub load about the $z_{\mathrm{h}}$ axis, for both hub configurations, peaks when the rotor is at $\psi=90^{\circ}$, resulting in a large $m_{\mathrm{h} z, \mathrm{~s}}^{1 \mathrm{P}}$ component. The magnitude of these loads in relation to each other is important for determining their impact on the non-rotating load components.

The rotating hub is connected to the main shaft, which is supported by a main bearing close to the hub and also may consist of additional bearings between the hub and gearbox. A rotation matrix models the transfer of loads from the rotating to non-rotating frame:

$\left[\begin{array}{c}m_{\mathrm{s} y} \\ m_{\mathrm{s} z}\end{array}\right]=\left[\begin{array}{cc}\cos \psi & -\sin \psi \\ \sin \psi & \cos \psi\end{array}\right]\left[\begin{array}{l}m_{\mathrm{h} y} \\ m_{\mathrm{h} z}\end{array}\right]$ 

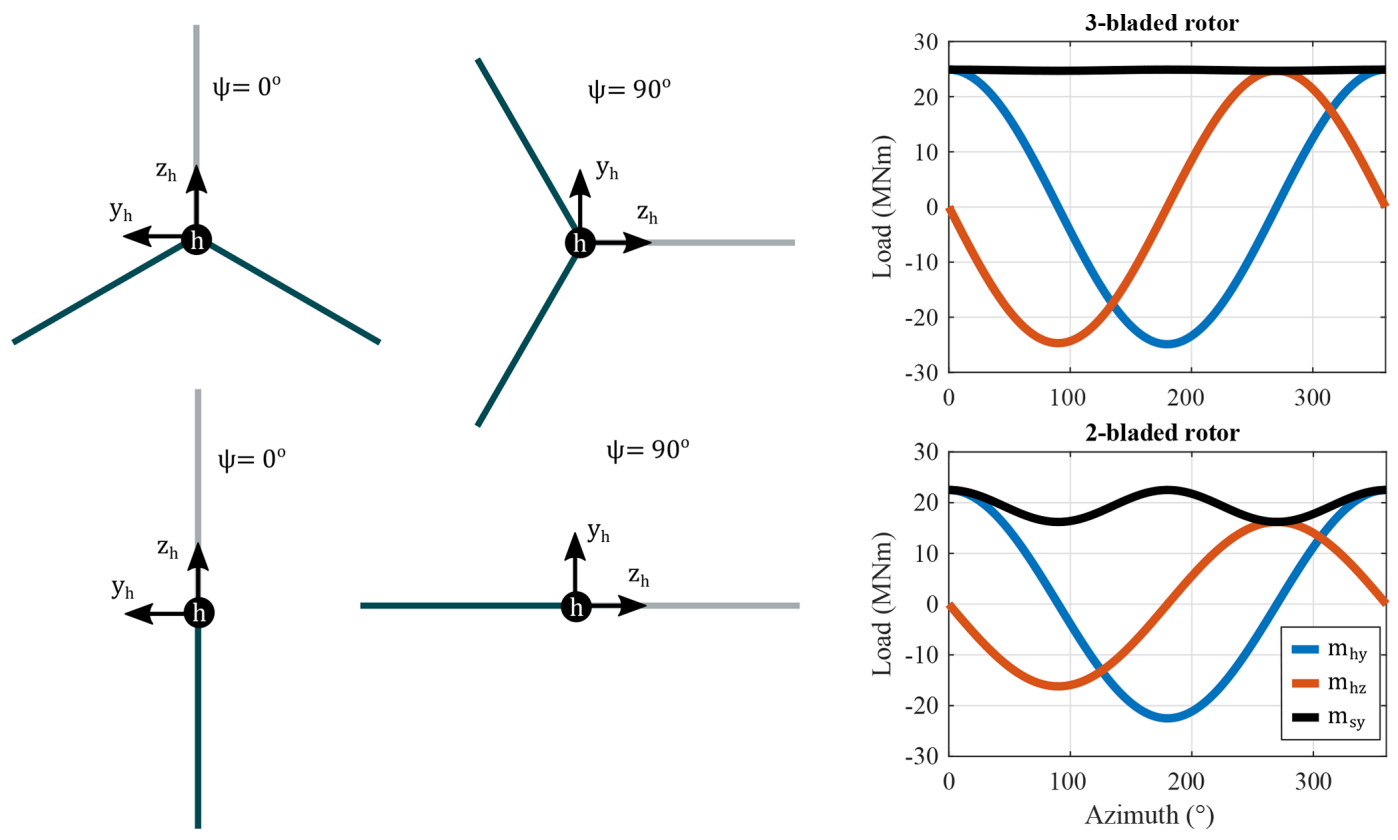

Figure 12. The hub axis $(h)$ as it rotates with the rotor azimuth angle $\psi$ for a three- and two-bladed rotor. Note that the $y_{\mathrm{S}}$ axis in Fig. 5 does not rotate, while the $y_{\mathrm{h}}$ axis in Fig. 12 does. An example time series of the hub loads $\left(m_{\mathrm{h} y}\right.$ and $\left.m_{\mathrm{h} z}\right)$ is shown to demonstrate the difference in the non-rotating main-bearing load $\left(m_{\mathrm{s} y}\right)$ for a three-bladed (upper) and two-bladed (lower) SUMR-13B rotor.

which results in the $1 \mathrm{P}$ hub loads mapping to large $0 \mathrm{P}$ and $2 \mathrm{P}$ load components. The large $2 \mathrm{P}$ loads result in large fatigue DELs on the non-rotating parts of two-bladed turbines. The hub configuration, including the number of blades, whether a teeter hinge is used, and IPC all have an impact on the fatigue loading of the main bearing.

\subsection{Number of blades}

To compare with the two-bladed SUMR-13B, a three-bladed SUMR-13B was designed using the same blade parameters described in Table 4. Peak and fatigue blade loads in both the flapwise and edgewise directions are unaffected by the change in the number of blades.

Loads on other turbine parts are, however, affected by the change in the number of blades. Hub loads on the two-bladed SUMR-13B are mostly about the $y_{\mathrm{h}}$ axis (see $m_{\mathrm{h} y, \mathrm{c}}^{1 \mathrm{P}}$ in Table 5), while three-bladed rotors are balanced in both directions. The hub loads in Table 5 can be mapped to the nonrotating frame by Eq. (23). The $1 \mathrm{P}$ harmonic in the rotating frame transfers to $\mathrm{OP}$ and $2 \mathrm{P}$ harmonics according to

$m_{\mathrm{s} y}^{0 \mathrm{P}}=\frac{1}{2}\left(m_{\mathrm{h} y, \mathrm{c}}^{1 \mathrm{P}}-m_{\mathrm{h} z, \mathrm{~s}}^{1 \mathrm{P}}\right)$

$m_{\mathrm{s} y}^{2 \mathrm{P}}=\frac{1}{2}\left(m_{\mathrm{h} y, \mathrm{c}}^{1 \mathrm{P}}+m_{\mathrm{h} z, \mathrm{~s}}^{1 \mathrm{P}}\right)$.

The 3P component is determined similarly based on the 2P harmonic load components by using Eq. (23).

Three-bladed rotors are advantageous due to these balanced hub loads, which effectively nullify the $2 \mathrm{P}$ load com- ponents and only contain a small 3P load on the non-rotating turbine components. The difference in magnitude of the $1 \mathrm{P}$ hub load harmonics is responsible for the greater loading on the non-rotating components of two-bladed rotors. Figure 13 shows more than a $20 \%$ reduction in main-bearing DEL for the three-bladed SUMR-13B, compared to the twobladed, fixed-hub SUMR-13B, even though the three-bladed rotor captures significantly more energy.

\subsection{Teeter and individual pitch control}

Historically, some two-bladed turbines have used a mechanical teeter hinge, which allows for rotation about an axis perpendicular to the main shaft at the shaft tip. Recently, with the advent of pitch regulated turbines, individual pitch controllers have been designed in order to mimic this action by changing the aerodynamic loads on the blades as they rotate. Both solutions reduce loading on the hub, which translates into reduced loading on the main bearing and other nonrotating components.

We have modeled a free-teetering hinge in FAST by enabling the teeter degree-of-freedom and setting a zero damping coefficient to the teeter motion. This free-teetering setup would provide the best configuration for reducing blade loads. A more realistic teeter hinge must account for friction, damping, and end stops (see, e.g., Schorbach et al., 2017).

The free-teetering hinge configuration completely eliminates the coupling between blade and hub loads, resulting in zero hub loads about the $y_{\mathrm{h}}$ axis. The relationship in Eq. (25) 
Table 5. Comparison of the $8.5 \mathrm{~ms}^{-1}$ hub load harmonics for two-bladed fixed, teeter, and IPC methods, as well as three-bladed (3b) rotors, in upwind and downwind positions. We analyze the cosine-cyclic hub load about the $y_{\mathrm{h}}$ axis $\left(m_{\mathrm{h} y, \mathrm{c}}\right.$, Fig. 12) and the sine-cyclic hub load about the $z_{\mathrm{h}}$ axis $\left(m_{\mathrm{h} z, \mathrm{~s}}^{1 \mathrm{P}}\right)$ because of their combined effect on non-rotating component loads. The different teeter and IPC methods are presented in Sect. 9.2.

\begin{tabular}{lllrr}
\hline Rotor orientation & Hub configuration & Rotor model & $\begin{array}{r}m_{\mathrm{hy}, \mathrm{c}}^{1 \mathrm{P}} \\
(\mathrm{kNm})\end{array}$ & $\begin{array}{r}m_{\mathrm{h}, \mathrm{s}}^{1 \mathrm{P}} \\
(\mathrm{kNm})\end{array}$ \\
\hline \multirow{5}{*}{ Downwind rotors } & Two-bladed fixed hub & $\begin{array}{l}\text { SUMR-13A } \\
\text { SUMR-13B }\end{array}$ & $\begin{array}{r}15500 \\
22500\end{array}$ & $\begin{array}{r}-8840 \\
-16200\end{array}$ \\
\cline { 2 - 5 } & Two-bladed teeter & Free teeter & 0 & -16900 \\
& Ideal teeter & 16200 & -16400 \\
\cline { 2 - 5 } & Two-bladed IPC & Blade IPC & 12300 & -16200 \\
& & Bearing IPC & 17700 & -16200 \\
\cline { 2 - 5 } & Three-bladed fixed hub & SUMR-13A (3b) & 7180 & -7220 \\
& SUMR-13B (3b) & 24900 & -24700 \\
\hline \multirow{2}{*}{ Upwind rotors } & Two-bladed fixed hub & SUMR-13A & 3780 & -3570 \\
& Three-bladed fixed hub & SUMR-13A (3b) & -526 & 543 \\
\hline
\end{tabular}
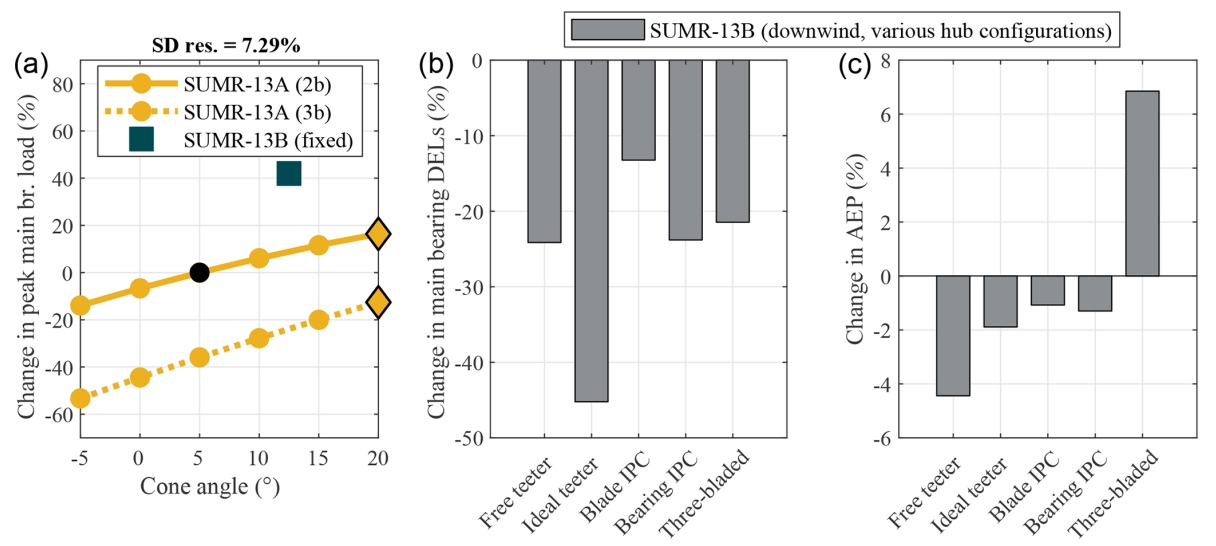

Figure 13. Change in peak main-bearing loads (a) for the SUMR-13A cone angle study (two- and three-bladed rotors) and the SUMR-13B fixed-hub configuration, change in main-bearing DELs (b) about the $y_{\mathrm{s}}$ axis (DELs about the $z_{\mathrm{s}}$ axis are within $5 \%$ of the $y_{\mathrm{s}}$-axis DELs) and change in AEP (c) for various hub configurations of the SUMR-13B, compared with the fixed-hub, two-bladed SUMR-13B final design described in Sect. 8.2. The DEL and AEP results from different hub configurations (b, c) are design loads computed directly from DLC simulations.

and harmonic loads in Table 5 suggest that main-bearing fatigue loads $\left(m_{\mathrm{sy}}^{2 \mathrm{P}}\right)$ increase when compared to the fixed-hub configuration. However, DLC simulations show that turbulence has a relatively minimal impact on the non-rotating components for this rotor with a free-teetering hinge, compared with all other rotors. In other words, the design loads for the main bearing are nearly equal to the harmonic loads, but in every other case there is a significant turbulent component, as mentioned in Sect. 6. Since this case is an outlier and behaves differently when mapping harmonic loads to turbulent loads, it is omitted from the transformation set of twobladed rotors. Instead of presenting the transformed load estimates and power capture, we present the design loads computed directly from DLC simulations in Fig. 13. However, the harmonic loads in Table 5 still illustrate how an optimal teeter design could mimic the balanced hub loads of threebladed rotors.

A more ideal teeter design could be achieved by selecting an appropriate teeter damping coefficient $d_{\text {teet }}$ that matches the $m_{\mathrm{h} y, \mathrm{c}}^{1 \mathrm{P}}$ and $m_{\mathrm{h} z, \mathrm{~s}}^{1 \mathrm{P}}$ load harmonics to minimize the mainbearing load $m_{\mathrm{sy}}^{2 \mathrm{P}}$. Since only one damping coefficient must be designed for all wind speeds, we minimize the mainbearing load using the wind speed distribution $p(u)$ by

$$
d_{\text {teet,opt }}=\operatorname{argmin}_{d_{\text {teet }}} \sum_{u \in U_{\text {teet }}} p(u) m_{\mathrm{s} y}^{2 \mathrm{P}} \text {, }
$$

where $U_{\text {teet }}$ is the set of wind speeds used to analyze the teeter damping, focused on below-rated operation, where the 
greatest fatigue contribution occurs. Main-bearing load cycle amplitudes $\left(m_{\mathrm{s} y}^{2 \mathrm{P}}\right.$ and $\left.m_{\mathrm{s} z}^{2 \mathrm{P}}\right)$ increase with wind speed due to the increased effect of wind shear, but lower wind speeds are far more probable than high wind speeds. Since our design goal is to reduce fatigue loads on the main bearing and other non-rotating components, we focus on below-rated wind conditions. The ideal teeter design greatly reduces the main-bearing fatigue loads, along with the fatigue loading on the other non-rotating components but reduces energy capture by $1.9 \%$, compared with the fixed two-bladed SUMR13B (Fig. 13b, c).

Alternatively, IPC can be used to mimic the rotor balancing of a teeter hinge by adding a time-varying pitch angle offset to each blade. An IPC algorithm was initially designed to focus on blade loads, which we call blade IPC in Table 5 and Fig. 13. The two-bladed IPC architecture used here was initially presented in van Solingen and van Wingerden (2015), which minimizes the teeter load:

$m_{\text {teet }}=\frac{1}{2}\left(m_{\mathrm{b} y, 1}-m_{\mathrm{b} y, 2}\right)$.

We have applied loop-shaping procedures (McFarlane and Glover, 1992) to fine tune the controller to reduce the $1 \mathrm{P}$ and 2P blade harmonics, which results in a decrease in the blade design load for the SUMR-13B (about $10 \%$ for flapwise peak and fatigue loads). The IPC algorithm was designed to operate in both above- and below-rated conditions, since the bulk of the fatigue loads occur in below-rated conditions, and the IPC must be active near rated in order to reduce the peak design load. Since this blade IPC is designed to reduce blade loads as much as possible, hub loads about the $y_{\mathrm{h}}$ axis are less than hub loads about the $z_{\mathrm{h}}$ axis (Table 5). Therefore, the blade IPC algorithm is not necessarily optimal for the main-bearing DELs.

Using the relationship in Eq. (25), we designed a bearing IPC algorithm with the goal of balancing the hub load components, such that $m_{\mathrm{hy}, \mathrm{c}}^{1 \mathrm{P}}=-m_{\mathrm{h} z, \mathrm{~s}}^{1 \mathrm{P}}$, to minimize $2 \mathrm{P}$ loading on the main bearing. Equivalently, $m_{\mathrm{h} y}^{1 \mathrm{P}}$ and $m_{\mathrm{h} z}^{1 \mathrm{P}}$ should be equal in magnitude and $90^{\circ}$ out of phase. Since $\left|m_{\mathrm{h} z}^{1 \mathrm{P}}\right|$ changes more slowly than $\left|m_{\mathrm{h} y}^{1 \mathrm{P}}\right|$, the $m_{\mathrm{h} z}$ signal is delayed by $90^{\circ}$ and the difference,

$m_{\mathrm{d}}=m_{\mathrm{h} y}-m_{\mathrm{h} z}\left(\psi-90^{\circ}\right)$,

can be fed back using the same architecture as the blade IPC because $m_{\mathrm{h} y}=2 m_{\text {teet }}$. Harmonic load estimates suggest better load mitigation than those in Fig. 13, so we present the DLC-based design loads directly from turbulent simulations. In general, dynamic control solutions are not as well estimated using harmonic load estimates, compared with changes to the rotor model using the same control because dynamics due to turbulence often drive control design. Other control methods were attempted to balance the load components in Eq. (25), which are further explored in Zalkind and Pao (2019).
If used in below-rated conditions, these load mitigation techniques reduce power capture, as shown in Fig. 13c. IPC can be designed so that it only operates in above-rated conditions, resulting in a negligible power loss. However, this reduces its effectiveness in constraining peak loads that occur close to rated wind speeds.

\subsection{Large cone angle effects}

The main bearing must support the weight of the rotor and thrust imbalance on the rotor due to shear, i.e.,

$m_{\mathrm{s} y}^{0}=m_{\mathrm{s} y, \text { grav }}^{0}+m_{\mathrm{s} y, \mathrm{shr}}^{0}$.

For downwind turbines, both components of Eq. (29) are positive, resulting in large, constant main-bearing loads about the $y_{\mathrm{s}}$ axis. For upwind turbines, the load due to gravity $m_{\mathrm{s} y \text {,grav }}^{0}$ is negative, while the load due to wind shear $m_{\mathrm{s} y, \text { shr }}^{0}$ is positive, which greatly reduces the steady-state main-bearing load for upwind turbines compared to downwind turbines. To quantify this difference, we analyze the harmonic load estimate of the peak main bearing $\left(m_{\mathrm{s} y, \text { Peak }}=\right.$ $m_{\mathrm{sy}}^{\mathrm{OP}}+m_{\mathrm{sy}}^{2 \mathrm{P}}$ ) for rotors with various cone angles (Fig. 13a).

The harmonic loads in Table 5 suggest there would be a significant change in the mean main-bearing load $m_{\mathrm{sy}}^{\mathrm{OP}}$ going from upwind to downwind rotor configurations. However, the design loads computed using DLC simulations show that turbulence contributes a large amount to the peak load experienced by the main bearing (Fig. 6) for both configurations. A downwind configuration, compared to the same rotor upwind (with cone angles of $\pm 5^{\circ}$, respectively) only increases the main-bearing load by about $15 \%$. Despite the larger total blade mass of the three-bladed rotors, two-bladed rotors still have a larger peak load due to the increased 2P loading and a larger turbulent load component. We see this same effect in the fatigue loading results of Fig. 13, which suggests that peak main-bearing loads could be reduced using the same methods as in Sect. 9.2. The larger SUMR-13B, however, has a non-negligible increase in the peak main-bearing load, due to combined increases in blade mass, blade length, and cone angle. These increased loads on the main-bearing transfer to the other non-rotating components, which we will analyze in the yaw-bearing and tower design studies.

\section{Yaw-bearing loads and nacelle layout}

The main bearing is mounted to the bedplate of the nacelle, which attaches to the yaw bearing, responsible for rotating the entire nacelle and rotor to align with the wind direction. The yaw bearing experiences similar loads to the main bearing; they peak near rated and at cut-out due to thrust effects and wind shear, respectively. A potential issue with downwind turbines is a large, mean $y_{\mathrm{y}}$-axis moment leading to large peak yaw-bearing loads, similar to the peak mainbearing load. However, peak loads on the yaw bearing can 

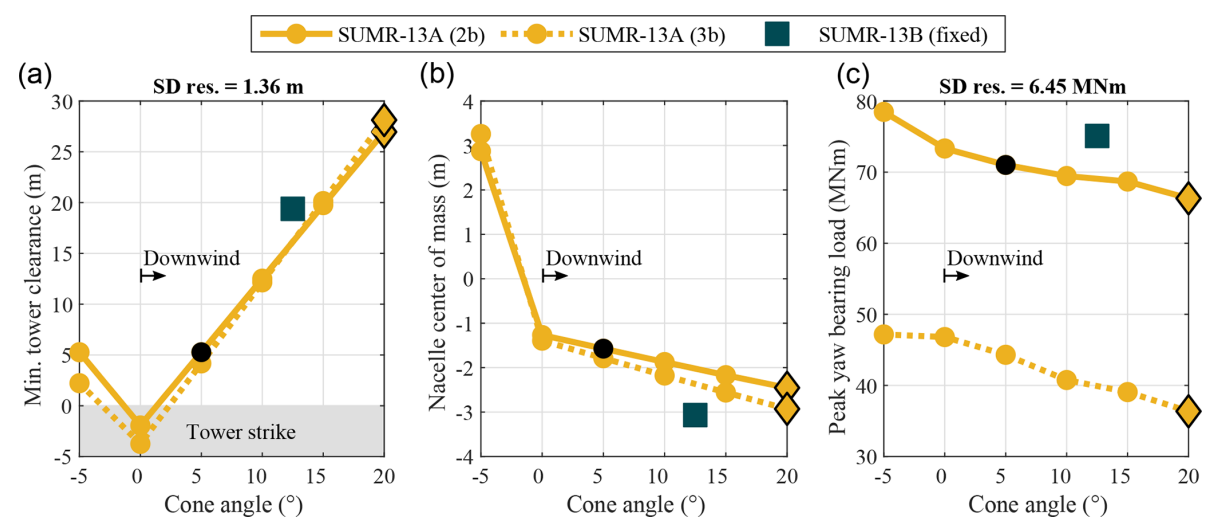

Figure 14. The tower clearance (a) resulting from upwind (negative cone angles) and downwind (positive cone angles) configurations, the nacelle center of mass (b) required to balance the rotors, and the peak yaw-bearing loads (c) of the balanced rotors.

be counteracted by properly balancing the nacelle center of mass atop the tower. We will study the different cone angle designs from Sect. 8.1 for two- and three-bladed rotors, as well as our SUMR-13B final design to investigate the effect of rotor cone angle and increased mass on nacelle design and yaw-bearing loads.

Large mean loads on the yaw bearing $\left(m_{\mathrm{yy}}^{\mathrm{OP}}\right)$ cause large peak loads that can be overcome by properly choosing the hub-to-tower overhang $x_{\mathrm{OH}}$ and the nacelle center of mass $x_{\mathrm{cm}}$ (as shown in Fig. 5). We use a simple method for determining the nacelle overhang: for upwind turbines, the nacelle overhang was set to that of the CONR-13 (-8.61 m), and for downwind turbines, we used the minimum possible overhang $(3.15 \mathrm{~m}$, equal to the radius of the tower at the nacelle). These hub-to-tower overhang values result in adequate tower clearance (the minimum perpendicular distance between the blade tip and the yaw axis $y_{z}$ ) when the cone angle is at least $5^{\circ}$ away from the tower (Fig. 14a). However, such an important design parameter would certainly be subject to verification using a detailed tower design and the full set of DLCs before deeming the tower safe from blade strike. Rotors with larger cone angles have large tower clearances, which is part of the motivation for their design.

To compare peak yaw-bearing loads across rotors, we adjust the nacelle center of mass so that mean yaw-bearing loads $\left(m_{\mathrm{yy}}^{0 \mathrm{P}}\right)$ are minimized in still air. The mean yaw-bearing load is linearly dependent on the component masses and center of masses:

$m_{\mathrm{y} y}^{0 \mathrm{P}}=g\left(m_{\mathrm{nac}} x_{\mathrm{cm}}+m_{\mathrm{rot}} x_{\mathrm{cm}, \mathrm{rot}}\right)$,

where $g$ is the acceleration due to gravity, $m_{\text {nac }}$ is the nacelle mass, $m_{\text {rot }}$ is the total rotor mass, and $x_{\mathrm{cm} \text {,rot }}$ is the rotor center of mass. The nacelle center of mass $x_{\mathrm{cm}}$ that sets the mean overturning yaw-bearing load to zero is

$x_{\mathrm{cm}}=-\frac{m_{\mathrm{rot}} x_{\mathrm{cm}, \mathrm{rot}}}{m_{\mathrm{nac}}}$.
Table 6. Component masses for placing the nacelle center of mass atop the tower.

\begin{tabular}{lr}
\hline Component & Mass (Mg) \\
\hline Nacelle & 1030 \\
Hub & 245 \\
Blade (two-bladed SUMR-13A) & 51.8 \\
Blade (three-bladed SUMR-13A) & 47.3 \\
Blade (two-bladed SUMR-13B) & 83.8 \\
\hline
\end{tabular}

The hub and nacelle masses are approximated using a lengthto-mass scaling factor of $\left(\frac{100}{63}\right)^{3}$ from the NREL $5 \mathrm{MW}$ reference turbine (Jonkman et al., 2009) and shown in Table 6 . The hub and nacelle masses are constant for all rotors throughout this study, but the rotor mass and center of mass vary.

Rotors with large downwind cone angles must have nacelle center of masses further upwind (negative values in Fig. 14, center). Given the nacelle mass in Table 6, moving the nacelle center of mass $1 \mathrm{~m}$ upwind reduces the mean (and peak) yaw moment by about $10 \mathrm{MNm}$. Due to the extra overhang necessary for upwind turbines, the center of mass location for the downwind turbines is closer to the tower than for the upwind turbines. By designing the proper hub-totower overhang and nacelle placement, the peak yaw loads are no more problematic for downwind rotors than upwind rotors. Once properly balanced, the peak yaw loads are primarily driven by the thrust imbalance due to wind shear, which decreases with increased cone angle (Fig. 14c). However, changing the nacelle center of mass is a non-trivial task that involves a detailed drivetrain and nacelle design. Fatigue loads (not shown) on the yaw bearing also depend on rotor thrust and decrease with increasing cone angles. The methods presented in Sect. 9.2 also reduce yaw-bearing loads. 

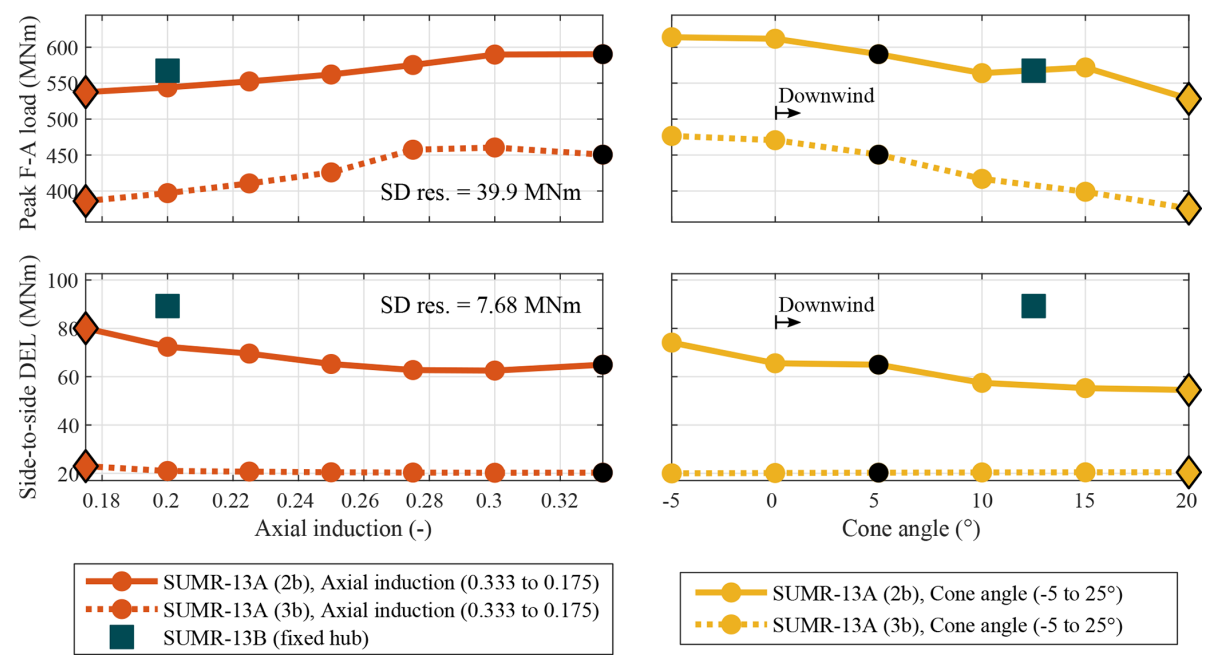

- SUMR-13A (2b), Cone angle $\left(-5\right.$ to $\left.25^{\circ}\right)$

" $=$ " w ' SUMR-13A (3b), Cone angle (-5 to $\left.25^{\circ}\right)$

Figure 15. Peak tower loads in the fore-aft (F-A) direction $\left(m_{\mathrm{t} y}^{\mathrm{Peak}}\right)$ and side-to-side DELs $\left(m_{\mathrm{t} x}^{\mathrm{DEL}}\right)$ for rotors with different axial induction factors (and corresponding blade length changes as discussed in Sect. 8.1; red), cone angles (yellow), and number of blades. The same loads for the SUMR-13B are also shown. Unless otherwise specified, the available rotor power is $13.9 \mathrm{MW}$, the axial induction is 0.333 , and the cone angle is $5^{\circ}$; the SUMR-13B is specified in Table 1 . The standard deviation of the residual for both load axes incorporates all of the presented design studies.

\section{Tower loads}

The yaw bearing is attached to the top of the tower, which must support the rotor-nacelle assembly and withstand large moments. We focus on the effect of rotor axial induction, cone angle, and the number of blades on peak loads in the fore-aft direction $m_{\mathrm{t} y}^{\text {Peak }}$ and fatigue loading in the side-toside direction $m_{\mathrm{t} x}^{\mathrm{DEL}}$.

Peak fore-aft tower loading is similar to the peak blade loads described in Sect. 8.1; with a maximum near rated wind speeds, they are largely driven by rotor thrust, which is most sensitive to changes in axial induction and cone angle. Lower axial induction rotors and downwind rotors can both reduce the peak tower load by as much as $20 \%$ (Fig. 15, left). Tower loads are not as sensitive to blade length. Longer blades increase the rotor thrust in below-rated wind speeds, but with a constant generator power, the pitch controller activates at lower wind speeds, constraining the peak tower load near rated. For rotors that capture the same amount of power, twobladed rotors experience about a $30 \%$ increase in peak tower fore-aft load when compared to three-bladed rotors because of a large difference in the turbulent sampling of the wind due to the increased chord lengths, an effect that is also present when looking at the tower DELs.

Besides having larger chord lengths that sample more turbulence than three-bladed rotors, two-bladed rotors also experience a resonance due to the tower design. Modern wind turbine towers are usually designed to be "soft-stiff", with a natural frequency between the $1 \mathrm{P}$ and $3 \mathrm{P}$ harmonics of the rotor (van der Tempel and Molenaar, 2003). When the 2P rotor speed interacts with the natural frequency of the tower, there are high fore-aft and side-to-side loads. Side-to-side tower DELs increase the most, since there is less aerodynamic damping from the rotor in this direction (Jonkman and Matha, 2011). One idea is to use a high-compliance tower structure (Bergami et al., 2014) or a floating substructure with a natural frequency below the $1 \mathrm{P}$ harmonic. However, a very low tower natural frequency causes tower motion to be perceived as a wind speed disturbance, resulting in speed regulation issues. Several studies have considered this, given the emergence of floating wind turbines (Jonkman and Matha, 2011), but to simplify our analysis, we have kept the same tower for all turbines: a scaled version of the NREL $5 \mathrm{MW}$ three-bladed reference model (Jonkman et al., 2009).

Our solution is to implement a speed avoidance controller that reduces the rotor speed as it approaches the critical rotor speed from below and increases it after, avoiding the critical speed as much as possible (Fig. 2b). Similar approaches have been used in two-bladed rotor field testing (Johnson et al., 2005). While this controller does reduce side-to-side fatigue loading, two-bladed rotors still experience 3 to 4 times the DELs that similar three-bladed rotors experience (Fig. 15). Longer, heavier blades with lower axial induction factors amplify this effect. Changing hub architectures also impacts the tower fatigue loads. Both teeter and IPC decrease the fore-aft loading while increasing the side-to-side loading.

The harmonic load simulations predict the same peak tower loads for both two- and three-bladed rotors, but turbulent simulations show a clear difference in the design load, as indicated in Fig. 15. Compared with other turbine parts, the transformed estimates of the tower loads have a large amount of uncertainty (Fig. 6). This uncertainty can be attributed to the source of these tower loads, which are highly dependent on turbulent gusts. 


\section{Model limitations, suggested improvements, and potential use}

When analyzing the design studies of Sects. 8-11, we have come across a few sources of uncertainty in the estimates of the transformed loads. When mapping the harmonic loads to the loads calculated using DLCs (Sect. 6), we see that a large component of the design load is due to turbulence, which primarily depends on the number of blades on the rotor, leading to different transformation coefficients for two- and threebladed rotors in Eq. (14). However, the turbulent component is also correlated with other model parameters, most notably rotor thrust. Highly coned downwind rotors reduce the rotor thrust and have a lower turbulent component than upwind rotors. Different levels of turbulence, besides Class IIB that was analyzed in this study, would result in different turbulent components and residuals of the transformation from harmonic to design load. Additionally, dynamic effects, like the problematic gust in Fig. 3, are not explicitly modeled in the harmonic model of Sect. 5. Thus, dynamic control solutions that appear promising in constant wind inputs should be ultimately verified in turbulent simulations.

Several improvements to the harmonic model could be made. For instance, the problematic gust events follow a similar profile in many instances; this could be an additional simulation added to the model's set of simulations. While outside the scope of this study, parked, fault, and shutdown cases can result in the largest design loads in practice, e.g., in Griffith and Richards (2014); they could be added with little computational expense. The transformation procedure could be streamlined by perhaps doing a single, exemplary turbulent simulation for each case to determine the turbulent component of each load.

The harmonic loads and their mapping to design load estimates used to evaluate design trade-offs provide a potential middle ground for wind turbine system engineering tools. The method is more realistic than simple scaling rules and static estimates but requires less computational effort than full sets of DLC simulations and therefore allows for an initial optimization over a wider range of configurations.

\section{Conclusions}

In this article, we presented a method for estimating wind turbine power capture and structural loads, which uses the harmonic components of signals from aeroelastic simulations in FAST with a constant, sheared inflow. The power and load estimates are mapped to design loads from power-producing design load cases and could be used for initial wind turbine system design or sensitivity analyses to model changes. We designed 42 different rotors with the goal of reducing the cost of wind energy through increased power capture and reduced capital expenditures. Power capture and structural loads are analyzed for blades longer than $100 \mathrm{~m}$ in both upwind and downwind configurations, with two- and three-bladed rotors, leading to an updated design, the SUMR-13B, with longer, more slender blades that align with industry trends. A series of detailed design studies was performed, with the following conclusions:

- Low axial induction rotors using longer blades with smaller chord lengths can capture more energy while constraining peak operational blade loads.

- As rotor size increases, due to increasing blade mass, edgewise blade loading becomes a critical designdriving load and may ultimately constrain the size of wind turbine rotors.

- Downwind, coned rotors can significantly reduce peak operational blade loads but capture less energy than rotors with lower cone angles.

- Downwind, coned rotors will experience slightly larger (about 15\%-25\%) peak main-bearing loads than upwind turbines, but the effect is amplified with increasing blade length, mass, and cone angle.

- Peak yaw-bearing and tower loads are not problematic for downwind rotors as long as the nacelle is properly balanced on the tower.

- Two-bladed rotors experience significantly greater loading on the non-rotating parts compared to three-bladed rotors, unless a teeter hinge or individual pitch control is utilized. In these cases, the loading is comparable but with a loss in power.

- Two-bladed rotors will require either speed avoidance control or a different tower design to avoid resonance with the $2 \mathrm{P}$ frequency of the rotor.

We believe that our model has provided future wind turbine designers with a method for more quickly analyzing design trade-offs, and our design studies can serve as a reference for future large rotor designs.

Code and data availability. The code and/or data from this study can be made available upon request.

Author contributions. All authors contributed to the baseline models and design direction of the SUMR rotors. DSZ developed the harmonic model, transformation, and closed-loop controllers, carried out simulations, and prepared the visualizations and manuscript. GKA designed the aerodynamic properties of the various rotors, MC investigated the structural properties, DPM investigated the teeter configurations, and CJB visualized the design studies. KEJ provided a thorough review of initial and the final drafts. EL developed the original rotor concept and outlined system-level goals. DTG provided experience on edgewise loading for large rotors, guided the structural design process, and reviewed the article. MSS reviewed the article. LYP had a supervising function and 
guided the study, helped formulate the article concept, and reviewed multiple drafts of the article.

Competing interests. The authors declare that they have no conflict of interest.

Acknowledgements. The information, data, or work presented herein was funded in part by the Advanced Research Projects Agency - Energy (ARPA-E), US Department of Energy, under award no. DE-AR0000667. The views and opinions of authors expressed herein do not necessarily state or reflect those of the United States Government or any agency thereof. Support from the HanseWissenschaftskolleg Institute for Advanced Study (Delmenhorst, Germany) and a Palmer Endowed Chair Professorship are also gratefully acknowledged. The authors would also like to acknowledge Paul Veers for his helpful review of this article on behalf of the National Renewable Energy Laboratory and the entire SUMR team for the discussions that ultimately motivated these design studies, as well as their work on the many design aspects of the baseline rotor models.

Financial support. This research has been supported by the Advanced Research Projects Agency - Energy (grant no. DEAR0000667).

Review statement. This paper was edited by Raúl Bayoán Cal and reviewed by Christopher Kelley and one anonymous referee.

\section{References}

Ananda, G. K., Bansal, S., and Selig, M. S.: Aerodynamic design of the 13.2 MW SUMR-13i wind turbine rotor, in: 2018 Wind Energy Symposium, AIAA SciTech Forum (AIAA 2018-0994), available at: https://arc.aiaa.org/doi/10.2514/6.2018-0994 (last access: 30 October 2019), 2018.

Bak, C., Zahle, F., Bitsche, R., Kim, T., Yde, A., Henriksen, L. C., Natarajan, A., and Hansen, M. H.: Description of the DTU 10-MW reference wind turbine, Tech. Rep. I-0092, DTU Wind Energy, available at: https://orbit.dtu.dk/files/55645274/ The_DTU_10MW_Reference_Turbine_Christian_Bak.pdf (last access: 30 October 2019), 2013.

Berg, J. and Resor, B.: Numerical manufacturing and design tool (NuMAD V2.0) for wind turbine blades: user's guide, Tech. Rep. SAND2012-728, Sandia National Laboratories, available at: https://energy.sandia.gov/wp-content/gallery/uploads/ NuMAD_UserGuide_SAND2012-7028.pdf (last access: 30 October 2019), 2012.

Bergami, L., Madsen, H. A., and Rasmussen, F.: A two-bladed teetering hub configuration for the DTU $10 \mathrm{MW}$ RWT: loads considerations, in: European Wind Energy Association (EWEA), 1-8, available at: http://orbit.dtu.dk/files/ 89872770/prod11395144001651.leob_Ewea2B1_ver2.pdf (last access: 30 October 2019), 2014.
Bertelè, M., Bottasso, C. L., Cacciola, S., Daher Adegas, F., and Delport, S.: Wind inflow observation from load harmonics, Wind Energ. Sci., 2, 615-640, https://doi.org/10.5194/wes-2615-2017, 2017.

Bortolotti, P., Bottasso, C. L., and Croce, A.: Combined preliminary-detailed design of wind turbines, Wind Energ. Sci., 1, 71-88, https://doi.org/10.5194/wes-1-71-2016, 2016.

Bottasso, C. L. and Cacciola, S.: Model-independent periodic stability analysis of wind turbines, Wind Energy, 18, 865-887, https://doi.org/10.1002/we.1735, 2015.

Bottasso, C. L., Croce, A., Riboldi, C. E., and Nam, Y.: Multi-layer control architecture for the reduction of deterministic and nondeterministic loads on wind turbines, Renew. Energy, 51, 159169, https://doi.org/10.1016/j.renene.2012.08.079, 2013.

Budynas, R. G. and Nisbett, J. K.: Shigley's Mechanical Engineering Design, 9th Edn., McGraw-Hill, New York, NY, available at: https://eclass.teicrete.gr/modules/document/file.php/TM114/ shigley-machine-design-.pdf (last access: 30 October 2019), 2015.

Dimitrov, N., Kelly, M. C., Vignaroli, A., and Berg, J.: From wind to loads: wind turbine site-specific load estimation with surrogate models trained on high-fidelity load databases, Wind Energ. Sci., 3, 767-790, https://doi.org/10.5194/wes-3-767-2018, 2018.

Døssing, M.: Optimization of wind turbine rotors - using advanced aerodynamic and aeroelastic models and numerical optimization, Tech. Rep. Ris $\varnothing-P h D$ No. 69, Technical University of Denmark, available at: https:/www.osti.gov/etdeweb/servlets/purl/ 1021046 (last access: 30 October 2019), 2011.

Drela, M.: XFOIL: an analysis and design system for low Reynolds number airfoils, in: Low Reynolds Number Aerodynamics, edited by: Mueller, T. J., Springer, Berlin, Heidelberg, 1-12, 1989.

Drela, M. and Giles, M.: Viscous-inviscid analysis of transonic and low Reynolds number airfoils, AIAA J., 25, 1347-1355, https://doi.org/10.2514/3.9789, 1987.

Dykes, K., Ning, A., King, R., Graf, P., Scott, G., and Veers, P.: Sensitivity analysis of wind plant performance to key turbine design parameters: a systems engineering approach, Tech. Rep. NREL/CP-5000-60920, National Renewable Energy Laboratory, available at: https://www.nrel.gov/docs/fy14osti/60920. pdf (last access: 30 October 2019), 2014.

Griffith, D. T.: The SNL100-01 blade: carbon design studies for the Sandia 100-meter blade, Tech. Rep. SAND2013-1178, Sandia National Laboratory, available at: http://prod.sandia.gov/ techlib/access-control.cgi/2013/131178.pdf (last access: 30 October 2019), 2013a.

Griffith, D. T.: The SNL100-02 blade: advanced core material design studies for the Sandia 100-meter blade, Tech. Rep. SAND2013-10162, Sandia National Laboratory, available at: http://energy.sandia.gov/wp-content/gallery/uploads/dlm_ uploads/1310162.pdf (last access: 30 October 2019), 2013b.

Griffith, D. T.: Structural design of the SUMR-13 wind turbine blade, Tech. Rep. M2.5.9, Advanced Research Projects Agency - Energy (ARPA-E), Segmented Ultralight Morphing Rotor (SUMR), available at: https://arpa-e.energy.gov/?q= slick-sheet-project/ultra-large-wind-turbine (last access: 30 October 2019), 2017.

Griffith, D. T. and Ashwill, T. D.: The Sandia 100-meter all-glass baseline wind turbine blade: SNL100-00, Tech. 
Rep. SAND2011-3779, Sandia National Laboratory, available at: https://energy.sandia.gov/wp-content/gallery/uploads/ 113779.pdf (last access: 30 October 2019), 2011.

Griffith, D. T. and Richards, P. W.: The SNL100-03 blade: design studies with flatback airfoils for the Sandia 100meter blade, Tech. Rep. SAND2014-18129, Sandia National Laboratory, available at: http://energy.sandia.gov/wp-content/ gallery/uploads/dlm_uploads/1418129.pdf (last access: 30 October 2019), 2014.

Hayman, G. J.: MLife theory manual for version 1.00, Tech. rep., National Renewable Energy Laboratory, available at: https://nwtc.nrel.gov/system/files/MLife_Theory.pdf (last access: 30 October 2019), 2012.

Ichter, B., Steele, A., Loth, E., Moriarty, P., and Selig, M.: A morphing downwind-aligned rotor concept based on a 13-MW wind turbine, Wind Energy, 19, 625-637, https://doi.org/10.1002/we.1855, 2016.

International Electrotechnical Commission: Wind turbines - part 1: design requirements, Tech. Rep. IEC 61400-1:2005(E), available at: https://www.saiglobal.com/pdftemp/previews/osh/iec/ iec61000/61400/iec61400-11\%7Bed3.01\%7Den.pdf (last access: 30 October 2019), 2005.

Jenkins, N., Burton, A., Sharpe, D., and Bossanyi, E.: Wind Energy Handbook, John Wiley \& Sons Ltd, UK, 2001.

Johnson, K., Fingersh, L. J., and Wright, A. D.: Controls advanced research turbine: lessons learned during advanced controls testing, Tech. Rep. NREL/TP-500-38130, National Renewable Energy Laboratory, available at: https://pdfs.semanticscholar.org/ 6f07/7588aca0278bc87e6f2b9dba5e4492960d44.pdf (last access: 30 October 2019), 2005.

Jonkman, B. and Kilcher, L.: TurbSim user's guide: version 1.06.00, Tech. Rep. TP-500-39797, National Renewable Energy Laboratory, available at: https://nwtc.nrel.gov/system/files/TurbSim.pdf (last access: 30 October 2019), 2012.

Jonkman, J. M.: The new modularization framework for the FAST wind turbine CAE tool, in: 51st AIAA Aerospace Sciences Meeting, available at: https://www.nrel.gov/docs/fy13osti/57228.pdf (last access: 30 October 2019), 2013.

Jonkman, J. M. and Matha, D.: Dynamics of offshore floating wind turbines - analysis of three concepts, Wind Energy, 14, 557-569, https://doi.org/10.1002/we.442, 2011.

Jonkman, J. M., Butterfield, S., Musial, W., and Scott, G.: Definition of a 5-MW reference wind turbine for offshore system development, Tech. Rep. NREL/TP-500-38060, National Renewable Energy Laboratory, available at: https://www.nrel.gov/docs/ fy09osti/38060.pdf (last access: 30 October 2019), 2009.

Loth, E., Fingersh, L., Griffith, D., Kaminski, M., and Qin, C.: Gravo-aeroelastically scaling for extreme-scale wind turbines, in: 35th AIAA Applied Aerodynamics Conference, 5-9 June 2017, Denver, Colorado, 1-11, https://doi.org/10.2514/6.2017-4215, 2017a.

Loth, E., Steele, A., Qin, C., Ichter, B., Selig, M. S., and Moriarty, P.: Downwind pre-aligned rotors for extremescale wind turbines, Wind Energy, 20, 1241-1259, https://doi.org/10.1002/we.2092, 2017b.

McFarlane, D. and Glover, K.: A loop-shaping design procedure using $H_{\infty}$ synthesis, IEEE T. Automat. Control, 37, 759-769, https://doi.org/10.1109/9.256330, 1992.
McWilliam, M. K., Barlas, T. K., Madsen, H. A., and Zahle, F.: Aero-elastic wind turbine design with active flaps for AEP maximization, Wind Energ. Sci., 3, 231-241, https://doi.org/10.5194/wes-3-231-2018, 2018.

Mone, C., Hand, M., Bolinger, M., Rand, J., Heimiller, D., and Ho, J.: 2015 cost of wind energy review, Tech. Rep. NREL/TP6A20-66861, National Renewable Energy Laboratory, available at: https://www.nrel.gov/docs/fy17osti/66861.pdf (last access: 30 October 2019), 2015.

Natarajan, A., Hansen, M. H., and Wang, S.: Design load basis for offshore wind turbines, Tech. Rep. E-0133, DTU Wind Energy, available at: https://orbit.dtu.dk/files/126478218/DTU_ Offshore_Design_Load_Basis_Rev_0.pdf (last access: 30 October 2019), 2016.

Ning, A., Damiani, R., and Moriarty, P. J.: Objectives and constraints for wind turbine optimization, J. Solar Energ. Eng., 136, 041010, https://doi.org/10.1115/1.4027693, 2014.

Noyes, C., Qin, C., Loth, E., and Schreck, S.: Measurements and predictions of wind turbine tower shadow and fairing effects, J. Wind Eng. Indust. Aerodynam., 179, 297-307, https://doi.org/10.1016/j.jweia.2018.06.012, 2018.

Pao, L. Y. and Johnson, K. E.: Control of wind turbines, IEEE Control Syst. Mag., 31, 44-62, https://doi.org/10.1109/MCS.2010.939962, 2011.

Pavese, C., Tibaldi, C., Larsen, T. J., Kim, T., and Thomsen, K.: Reduced design load basis for ultimate blade loads estimation in multidisciplinary design optimization frameworks, J. Phys.: Conf. Ser., 753, 62005, https://doi.org/10.1088/17426596/753/6/062005, 2016.

Pavese, C., Tibaldi, C., Zahle, F., and Kim, T.: Aeroelastic multidisciplinary design optimization of a swept wind turbine blade, Wind Energy, 20, 1941-1953, https://doi.org/10.1002/we.2131, 2017.

Peeringa, J., Brood, R., Ceyhan, O., Engels, W., and de Winkel, G.: Upwind $20 \mathrm{MW}$ wind turbine pre-design: blade design and control, Tech. Rep. ECN-E-11-017, Energy Research Centre of the Netherlands, available at: https://www.ecn. nl/publicaties/PdfFetch.aspx?nr=ECN-E--11-017 (last access: 30 October 2019), 2011.

Phillips, C. L., Parr, J., and Riskin, E.: Signals, Systems, and Transforms, 4th Edn., Prentice Hall Press, Upper Saddle River, NJ, USA, 2007.

Robertson, A., Sethuraman, L., Jonkman, J., and Quick, J.: Assessment of wind parameter sensitivity on ultimate and fatigue wind turbine loads: preprint, Tech. Rep. NREL/CP-5000-70445, National Renewable Energy Laboratory, available at: https://www. nrel.gov/docs/fy18osti/70445.pdf (last access: 30 October 2019), 2018.

Schorbach, V., Dalhoff, P., and Gust, P.: Teeter design for lowest extreme loads during end impacts, Wind Energy, 21, 1-14, https://doi.org/10.1002/we.2140, 2017.

Selig, M.: PROPID - software for horizontal-axis wind turbine design and analysis, available at: http://www.ae.illinois.edu/ m-selig/propid.html (last access: 30 October 2019), 1995.

Selig, M. and Tangler, J.: Development and application of a multipoint inverse design method for horizontal axis wind turbines, Wind Eng., 19, 91-105, 1995.

Sieros, G., Chaviaropoulos, P., Sørensen, J. D., Bulder, B. H., and Jamieson, P.: Upscaling wind turbines: theoretical and practical 
aspects and their impact on the cost of energy, Wind Energy, 15, 3-17, https://doi.org/10.1002/we.527, 2012.

Tibaldi, C., Hansen, M. H., and Zahle, F.: Methods for systematic tuning of wind turbine controllers, Tech. Rep. E-0100, DTU Wind Energy, available at: http://orbit.dtu.dk/files/118777390/ Wind_Energy_E_0100.pdf (last access: 30 October 2019), 2015. van der Tempel, J. and Molenaar, D. P.: Wind turbine structural dynamics - a review of the principles for modern power generation, onshore and offshore, Wind Eng., 26, 211-222, https://doi.org/10.1260/030952402321039412, 2003.

van Solingen, E. and van Wingerden, J. W.: Linear individual pitch control design for two-bladed wind turbines, Wind Energy, 18, 677-697, https://doi.org/10.1002/we.1720, 2015.

Zahle, F., Tibaldi, C., Verelst, D. R., Bak, C., Bitsche, R., and Blasques, J. P.: Aero-elastic optimization of a $10 \mathrm{MW}$ wind turbine, in: 33rd Wind Energy Symposium, AIAA SciTech Forum (AIAA 2015-0491), 5-9 January 2015, Kissimmee, Florida, https://doi.org/10.2514/6.2015-0491, 2015.
Zalkind, D. S. and Pao, L. Y.: A harmonic model for loads analysis and control design of a 2-bladed wind turbine, in: 2019 AIAA SciTech Forum and Exposition, available at: https://sumrsite. files.wordpress.com/2018/08/harmonic-model-loads.pdf, last access: 30 October 2019.

Zalkind, D. S., Pao, L. Y., Martin, D. P., and Johnson, K. E.: Models used for the simulation and control of a segmented ultralight morphing rotor, in: 20th IFAC World Congress, 10-14 July 2017, Toulouse, France, 4564-4569, https://doi.org/10.1016/j.ifacol.2017.08.377, 2017. 